\title{
Household Composition and Gender Differences in Parental Time Investments
}

\author{
Andrew Bibler \\ University of Alaska Anchorage
}

April 4, 2017

\begin{abstract}
Recent research documents a female advantage in several important long-term outcomes among children raised in single-parent households, and highlights the importance of non-cognitive skills for explaining these gaps. Understanding the source of differences in non-cognitive skills is complicated due to the presence of many interrelated and often unobservable inputs. One potential explanation for such gaps is that boys and girls receive different levels of inputs in single-parent versus two-parent households. This paper provides empirical evidence that input levels change differentially by gender across household structures and hence may facilitate gender gaps in noncognitive skills. Using data from the Panel Study of Income Dynamics and accompanying Child Development Supplement, I estimate gender differences in parental time investments, defined as the amount of time parents spend participating in activities with the child, around changes in household composition. I find that, although both boys and girls experience reductions in parental time investments following a change from a two-parent to single-mother household, boys experience a larger reduction than girls. The largest difference is found in fathers' time investments on weekdays, for which boys lose an additional 24 minutes per day (35\% of average paternal weekday investments). Moreover, there is little to no evidence that single mothers compensate for the loss by increasing time investments to boys relative to girls.
\end{abstract}

Keywords: parental time investment, single-mother households, non-cognitive skills

JEL Codes: J12, J13, J16, J24, I20

Email: ajbibler@alaska.edu Phone: 907-786-5452 Address: UAA-ISER, 3211 Providence Dr. BOC3-301, Anchorage, AK 99508. I would like to thank Todd Elder, Stacy Dickert-Conlin, Scott Imberman, Michelle Maxfield, Kelly Vosters, Keith Teltser, Alex James and seminar participants at Michigan State University for helpful comments. This research was supported by a PreDoctoral Training Grant from the IES, U.S. Department of Education (Award \#R305B090011) to Michigan State University. Any opinions expressed here are those of the author and do not necessarily represent the views of the U.S. Department of Education. 


\section{Introduction}

Recent research has documented the poor performance of boys, especially those rasied in single-mother households, on a number of critical dimensions including cognitive performance [Cunha and Heckman, 2008, Heckman and Mosso, 2014, Kristoffersen et al., 2015], educational attainment [Autor et al., 2016b, Becker et al., 2010, Fortin et al., 2015, Goldin et al., 2006, Jacob, 2002, Owens, 2016], labor market outcomes [Autor et al., 2016a， Deming, 2016, Heckman et al., 2006, Heckman et al., 2013], arrests [Heckman et al., 2013], and risky behaviors [Heckman et al., 2006]. For example, among children born into married households, males are more likely than females to be employed at age 30, but the opposite is true among individuals born to non-married households [Autor et al., 2016a]. An underlying theme of this research is that differences in non-cognitive skills play an important role in generating gender gaps in the other outcomes. For example, Bertrand and Pan [2013] find that gender gaps in externalizing behavior $^{1}$ and school suspensions are substantially larger among children from single-mother households. Identifying and understanding the mechanisms that generate these gender gaps is important for designing policies or treatments to improve not only boys' non-cognitive skills, but to potentially improve the critically important outcomes mentioned above. In particular, determining how much of the single-mother household gender gaps in non-cognitive skills are due to differential returns to inputs versus differential levels of inputs is a first order concern. Bertrand and $\mathrm{Pan}^{2}$ find little support for a differential inputs story, and attribute the wider non-cognitive skill gaps found in single-mother households to differential returns to inputs. However, because of the inability of data sets to capture all relevant inputs, differences in omitted inputs can be misattributed as differential returns to observable inputs. This paper expands on prior literature by providing empirical evidence that differential levels of inputs may also contribute to the

\footnotetext{
${ }^{1}$ Externalizing behavior is based on a series of questions about the child's behavior, capturing the frequency with which the child acts out. More specifically, questions ask how frequently the child argues, fights, gets angry, acts impulsively, or disrupts activity. The externalizing behavior measures used by Bertrand and Pan [2013] are based on teacher ratings.

${ }^{2}$ Using data from the Early Childhood Longitudinal Survey - Kindergarten, they find that the fifth grade gender gap in externalizing behavior, favoring girls, is nearly twice as large among children from single-mother households [Bertrand and Pan, 2013]. Similarly, they find that the eighth grade gender gap in suspensions is more than twice as large among children from singlemother households.
} 
non-cognitive skill gaps.

The apparent effects of household structure on gender gaps in non-cognitive skills and long-run outcomes is striking, but disentangling the underlying mechanisms is complicated by the presence of many interrelated and often unobserved inputs. Parental time investments, defined in this paper as the amount of time that parents spend participating in activities with their children, ${ }^{3}$ are potentially important to the development of non-cognitive skills. If parental time investments are important in the production of non-cognitive skills, then differences in time investments could help explain gender gaps in non-cognitive skills and related outcomes (for example, non-cognitive skills promote the production of cognitive skills [Cunha and Heckman, 2008, Del Boca and Mancini, 2013, Del Boca et al., 2017, Heckman and Mosso, 2014]).

In this paper, I study gender gaps in parental time investments as they relate to household structure (e.g., two-parent versus single-mother households), and contribute to the literature by measuring changes in the level of parental time investments around transitions in household composition. The emphasis is on testing the plausibility of the hypothesis that gaps in non-cognitive skills are driven by differential time investments, while abstracting from the possibility that boys and girls may have differential returns to parental time investments. ${ }^{4}$ Because fathers tend to spend relatively more time with boys as they age [Baker and Milligan, 2013, Lundberg et al., 2007], and single-parent households are more often headed by the mother, growing up in a single-parent household could be more detrimental for boys in terms of time investments. ${ }^{5}$

Using the Panel Study of Income Dynamics (PSID) [2014] and the accompanying Child Development Supplement (CDS), I obtain direct measures of parental time investments and use within-child variation to estimate differential changes in investments by gender around changes

\footnotetext{
${ }^{3}$ As opposed to time that the parent is present but not participating in any activity with the child, which has been referred to as secondary [Lundberg et al., 2007] or accessible [Yeung et al., 2001] time in some prior research using PSID time diary data. In contrast, Lundberg et al. refer to time parents spend actively participating in activities with the child as direct time.

${ }^{4}$ Depending on how returns to parental time investments differ between boys and girls, differential returns could either compound or mitigate the effects of differential inputs on outcomes. However, this question is not directly addressed here. Rather, the focus is on testing whether investment levels differ across household types.

${ }^{5}$ Dahl and Moretti [2008] provide more general evidence of parental bias in favor of boys, showing that household structure is related to the sex of the first born child, and that fathers are more likely to obtain custody of sons following a separation.
} 
in household composition. While investments are lower for both boys and girls in single-mother homes relative to two-parent households, the reduction is more substantial for boys. I find the largest differences in paternal weekday investments, for which boys lose 24 minutes per day more than girls lose, which is about 35 percent of the average paternal weekday investment during the first CDS survey. I also find that boys suffer greater time investment losses than girls through paternal weekend investments, but the magnitude is more sensitive to specification. Combining the weekday and weekend data, I estimate that paternal investments decline by 2.3 hours more per week for boys in single-mother homes than for girls in single-mother homes, which is over 20 percent of the average weekly paternal investment during the first wave of the CDS. The investment gap is larger during adolescence, during which boys in single-mother homes lose over 3.3 hours per week more than girls. Estimating the gaps by activity type reveals that boys experience relatively large decreases in investments through leisure activities, ${ }^{6}$ which account for more of the gap than any other activity type. Furthermore, there is little to no evidence that mothers compensate for the additional loss by increasing investments to boys relative to girls. ${ }^{7}$ These findings support the hypothesis that time investments are a plausible mechanism to help explain the sensitivity of the magnitude of gender gaps in non-cognitive outcomes to household structure.

One advantage of the approach used in this paper is that, by focusing on children who underwent changes in household structure, the findings do not rely on cross-sectional comparisons of investments across individuals. Rather, the findings are based on comparisons of within-child changes in investments. ${ }^{8}$ Another advantage of this approach is the use of a direct measure of parental time investments, calculated from twenty-four hour time diaries collected as part of the Child Development Supplement to the PSID. While it is important to recognize that no single input measure can capture all relevant aspects of such a complex production process, the use of a direct measure of parental investments allows for transparency and clear interpretation of the results.

To better understand the source of the non-cognitive gender gaps, prior research attempts

\footnotetext{
${ }^{6}$ Using cross-sectional CDS data, Lundberg et al. [2007] also find more pronounced preferences of fathers to spend time with sons in active and passive leisure.

${ }^{7}$ This finding supports a cross-sectional finding from Lundberg et al. [2007] that mothers do not compensate for the loss in investments when the father is not present.

8 See Lundberg et al. [2007] and Yeung et al. [2001] for examples of research considering cross-sectional difference in time investments using PSID and CDS data.
} 
to quantify how much of the gap is due to differential inputs and how much is due to differential returns to inputs. Some prior studies find more support for differential returns to inputs. For example, Bertrand and Pan [2013] find no systematic differences in the home environment or investment measures $^{9}$ that explain the sensitivity of male outcomes to family structure and parental inputs. ${ }^{10}$ The authors conclude that, although inputs are lower for both boys and girls in single-mother relative to two-parent households, the behavior of boys is much more responsive to these inputs. This leads to a larger gender gap among those in single-mother homes and supports the hypothesis that gender gaps in non-cognitive skills are driven by differential returns to inputs. ${ }^{11}$ While investment levels and differential returns to investments both likely play a role in generating gender gaps in non-cognitive skills, separating the importance of returns and levels of each input is complicated by the fact that many inputs are correlated with household structure. The measured returns to one input can be conflated with the levels of and/or returns to omitted inputs [Autor et al., 2016a]. ${ }^{12}$ The main finding of this paper, that the relationship between household structure and parental time investments differs by gender, adds to the literature on the relative contributions of differential inputs and differential returns to inputs to the gender gaps in non-cognitive skills by providing evidence that differential inputs may play a role in determining the size of the gender gaps.

Investigating whether investment levels depend on household structure differentially for boys and girls also adds to the evidence on the role of childhood environment, as opposed to pre-natal differences, in explaining the gender gap. More generally, the post-natal environment, including neighborhood and school quality, appears to play a role in the production of non-cognitive

\footnotetext{
${ }^{9}$ Bertrand and Pan [2013] use data from the Early Childhood Longitudinal Study - Kindergarten Cohort. They use input measures such as the HOME index, Warmth index, and whether the child was spanked last week, all of which are correlated with household structure. The HOME index is based on parent responses to six questions about the activities that the child participates in and activities the parent participates in with the child. All of the questions were asked during the child's kindergarten year. The Warmth index, also referred to as emotional supportiveness, is based on parent responses to a series of statements about their child, e.g. child and I often have warm, close times together and being a parent is harder than I thought it would be. Responses were given in the Spring of the child's kindergarten year. See Bertrand and Pan, 2013 for more details.

${ }^{10}$ Likewise, Bertrand and Pan [2013] also do not find systematic differences in the gender differentials by characteristics of kindergarten class environment.

${ }^{11}$ Other research shows that more educated and higher income parents invest more time into their children [Guryan et al., 2008]. Unless this varies differentially by gender, it could not on its own explain the difference in gender gaps across the hh/ses distribution found in Autor et al. [2016a].

${ }^{12}$ Autor et al. [2016a] make a similar point about parental investments varying differentially between boys and girls. This paper tests whether this is true for parental time investments.
} 
skills [Autor et al., 2016a, Autor et al., 2016b, Chetty et al., 2016a, Chetty and Hendren, 2016, Chetty et al., 2016b]. Autor et al. [2016a] compare a fetal origins explanation with a post-natal environment explanation for the changes across the SES distribution in within-family gender gaps in long-run outcomes. They find that changes in within-family gender gaps are unrelated to pre-natal differences, suggesting that the post-natal environment is critical in explaining the changing gender gap across the SES gradient and household structures. This finding is supported by the particular sensitivity of boys to neighborhood characteristics [Chetty and Hendren, 2016]. However, gender gaps remain even after accounting for differences in school and neighborhood quality, ${ }^{13}$ suggesting that other mechanisms are at play. Because non-cognitive skills continue to develop at later stages in child development (i.e. adolescence) [Heckman and Mosso, 2014], the importance of time investments in shaping non-cognitive skills and related outcomes is plausible even for individuals experiencing investment losses during adolescence.

After documenting the gender gaps in the levels of parental investments, I employ the same methods based on individual fixed effects to measure changes in externalizing, internalizing, and positive behavior $^{14}$ around changes in household composition. Counterintuitively, boys display better externalizing and positive behavior in single-mother homes relative to girls, which suggests a more puzzling relationship between time investments, household structure, and child behavior. However, these findings are based on parental ratings, which is a limitation of the CDS data. One concern with parent-based behavioral ratings is that parental perception of child behavior could change differentially for boys and girls around changes in household structure, even if actual behavior does not.

A description of the PSID and CDS data is provided in Section 2. Section 3 discusses the estimation procedure, which is based on individual fixed effects. Section 4 outlines results on the relationship between household composition and the gender gap in time investments, and a

\footnotetext{
${ }^{13}$ Autor et al. [2016a] find that neighborhood and school quality can explain at most one-third of the sibling gender gap.

${ }^{14}$ These are three behavioral measures included in the CDS data. Externalizing behavior is discussed more in footnote 1 . Internalizing behavior is based on a series of questions about the child's frequency of exhibiting some inwardly negative behavior. Positive behavior is based on a series of questions that ask how "like" the child it is to exhibit some positive behavior. Ratings are based on responses of the child's primary caregiver.
} 
brief discussion of the changes in behavioral measures around changes in household composition. Section 5 concludes and discusses the implications of the main findings.

\section{Data}

The CDS is a survey that was administered to children of PSID families in three waves (1997, 2002/2003, and 2007), and includes time diaries, and surveys of the children and their parents. The most critical component of the CDS for the purpose of this paper is the collection of twenty-four hour time diaries that catalog the activities of each child for one weekday and one weekend day. The diary data are at the activity level and include information on the duration and participants for each activity. I use the time diaries to construct measures of parental investments by summing time that each parent spent participating in activities with the child in each diary. ${ }^{15}$ Every child in the CDS was assigned one randomly selected weekend day and weekday to record their activities. The first wave of the CDS includes children under age 13, and they are eligible for the CDS until they turn 18. ${ }^{16}$ About 2,900 participants completed at least one time diary for CDS-I. More than 2,500 and 1,400 completed at least one diary for CDS-II and CDS-III, respectively. These add up to a total of 6,915 child-year observations. A total of 3,330 children completed at least one time diary in any period, and 1,086 completed at least one in all three waves. More than 1,400 completed at least one diary for exactly two of the waves.

There are two features of the data that are critical for the following analysis. The first is the presence of the time diaries used to calculate parental investments. Investments are calculated by summing time spent participating in activities with mother/father ${ }^{17}$ across activity-level

\footnotetext{
${ }^{15}$ In the time diary data, there are two indicators that describe participation and presence of each parent for every activity. One of them is an indicator for whether the parent was participating in the activity with the child. The other tells whether the parent was present, but not participating. I use the indicator for whether the parent was participating in the activity to construct the time investment measures.

${ }^{16}$ The age limits refer to the child's age during an initial screening. There are a small number of cases for which the child's age was outside of these limits at the point that the time diary data was recorded.

${ }^{17}$ The investment measures only include time with biological/adoptive parents. Similarly, when referring to parental presence in the household, I am referring to biological/adoptive parents only. For example, a child who lives in the same household as their biological/adoptive mother and a step-father is considered to be living in a single-mother household for the purposes of this study.
} 
data for each child. This is done separately for each weekend and weekday diary. In addition, I construct weekly investment measures to help summarize total investments by summing the weekday investment multiplied by five with the weekend investment multiplied by two. Second, I use information from the CDS surveys ${ }^{18}$ to construct household composition indicators for each childwave observation, including presence of the child's biological/adoptive mother and father. I focus on comparing time investments for children in two-parent and single-mother households.

Figures 1 through 4 display cross-sectional differences in investments across gender and household type from wave I of the CDS. Figure 1 graphs local polynomials of investments by age, for boys and girls who were in two-parent or single-mother households during the first wave. Weekday time spent with mothers decreases dramatically with age for all gender and household type combinations. The average investments across these groups are within about thirty minutes of each other at every age in Figure 1. However, at ages where investments differ, it is generally true that mothers invest more time in daughters than sons, and that mothers in two-parent households spend more time participating in activities with their children. Figure 2 displays the analogous estimates for maternal weekend investments by age. The overall levels of the investments are higher on weekend days, and investment gaps between genders and household types are also more pronounced. For example, in Figure 1 the patterns for weekday maternal investments to girls are almost identical for those in two-parent and single-mother households, but in Figure 2 single-mother's weekend investments to girls are lower at every age than their two-parent household counterparts. The gap is roughly between thirty and sixty minutes at every age, which is a significant gap relative to that in Figure 1 where the lines are almost indistinguishable at some ages. Similarly, there is a persistent gap between household types for maternal investments to boys across all ages, with boys in two-parent households receiving larger investments. Furthermore, the gender gap in mother's weekend investments appears to widen with age, with mothers spending more time participating in activities with girls than with boys. Both Figures 1 and 2 demonstrate the importance of the child's age when considering time investments, as investments decrease sharply with age. For example, mothers invest between 6 and 6-1/2 hours on weekend days to their infant

\footnotetext{
${ }^{18}$ The household structure variables are constructed from the Primary Caregiver Child File, which is part of the CDS.
} 
and toddler daughters, but that number is roughly 4 hours for 12 and 13 year olds.

Figures 3 and 4 graph paternal investments from the weekday and weekend diaries, respectively. Fathers generally invest less time than mothers do across all household types and genders, but the decrease in investments with age is less drastic, especially for boys. In fact, Figure 3 shows that weekday paternal investments are similarly low for both boys and girls in single-mother households across all ages. A slight increase in paternal weekend investments to boys in single-mother homes, shown in Figure 4, leads to a small gap that appears to increase with age. The increasing gender gap in weekend paternal investments is more apparent in two-parent homes. From Figure 4 , both boys and girls in two-parent homes receive more than 4 hours in weekend paternal investments up until about age 5, but a steady decline in weekend paternal investments for girls in two-parent homes leads to that number dropping below 3 hours around age 12. However, weekend paternal investments for boys in two-parent homes remain steady at around 4 hours for all ages represented in the graph.

One implication of these investment patterns, particularly for boys in two-parent households, is that the proportion of total investments that come from fathers is increasing with age. This is shown more directly in Figures 5 and 6, which graph the proportion of the total parental investments ${ }^{19}$ that come from each parent for those in two-parent households in the first wave for boys and girls, respectively. The proportions are roughly the same for infant and toddler boys and girls, with each receiving almost 70 percent of total parental investments from their mother. The proportions change quite differently for boys and girls as they age. For girls, maternal investments remain relatively high, never dropping below about 65 percent of total parental investments. However, maternal investments dip below 55 percent of total parental investments by about age 12 for boys. Another implication of the gender differences in the investments-age relationship is that one might expect the differential effect of household composition on parental time investments to differ by age. The increasing relative importance of paternal investments for boys, apparent in Figures 4 and 5, suggests that the potential for investment losses, relative to girls, increases with age.

\footnotetext{
${ }^{19}$ Total investments, Total $_{i}$, were calculated by weighting the weekday, $W D_{i}$, and weekend, $W E_{i}$, investments to construct a weekly investment, such that Total $i=5 \cdot W D_{i}+2 \cdot W E_{i}$. The weekly measure of time spent with each parent divided by the total weekly measure is the proportion of total parental investment from that parent. The two values add to one by construction.
} 
Two important points of Figures 1 - 6 are that investments generally decline with age and that the relationship between investments and age differs by gender. These patterns could reflect the way parents spread their time with multiple children (Price, 2008) and the apparent preference of fathers to spend relatively more time with their sons (Baker and Milligan, 2013). In most cases, across all age groups and household structures, mothers spend a little more total time with girls, and fathers spend a little more with boys, on average. The figures demonstrate how important age is when evaluating time investments and suggests that using flexible controls for age is necessary in the analysis that follows.

Table 1 summarizes the time investment variables and covariates by gender and household type. In particular, I separate out the individuals who underwent a change in household structure, because they are critical for estimation. Columns 3 and 4 display average characteristics for boys who underwent a change at some point. Column 3 includes boys who lived with both parents in the first period, meaning that the change in structure for them is going from living with both parents to living with less than both parents. On the other hand, column 4 includes individuals who underwent changes, but did not have both parents in the household in the first period. Columns 7 and 8 display the averages for girls who underwent a change in household composition at some point. The first row summarizes total weekly maternal investments, which was constructed by summing weekday investments (row 2) multiplied by five with weekend investments (row 3) multiplied by two. Girls receive larger maternal investments than boys across all household types. Girls who were always in two-parent households received about 26.6 hours in maternal investments per week, relative to 24.8 hours per week for boys. The gap in maternal investments for children in two-parent households that eventually split, comparing column 6 with column 2, is about 3 hours per week, with girls receiving more investments. Both boys and girls in households that eventually split received larger maternal investments than those who were always in a two-parent household. From column 3, boys in families that eventually split received 25.5 hours per week on average, and those in households that never split received 24.8 hours per week. Similarly, girls in twoparent households that eventually had a change in composition received 27.4 hours per week in maternal investments, but those in two-parent households that never split received 26.6 hours per 
week. These comparisons may be misleading, because the household structure categories are also correlated with age. For example, girls in two-parent households that never experience a change are just under 7 years old on average, but the average age of girls in two-parent households that eventually split is under 5 years. The difference is similar for boys. This, along with Figures $1-4$, demonstrates why it is important to control flexibly for age when estimating gender gaps in the relationship between investments and household structure. Not only is age correlated with investments differentially by gender, it is also correlated with household structure. With that in mind, it is similarly true that boys in two-parent households that eventually split received more paternal investments than those who were always in two-parent households, 16.7 and 16.3 hours per week, respectively. However, the opposite is true for girls, with girls who were always in a two-parent household receiving nearly 2 hours more per week in paternal investments, despite being roughly 2 years older on average.

From column 3, boys who experience a change in household composition but are in a twoparent household during wave I are about 2 years younger than boys who do not experience a change and are in a two-parent household at wave I, 4.6 years old and 6.5 years old, respectively. Boys in two-parent households who eventually see a change in household composition also have a little over one sibling in the household on average, whereas those in two-parent households who experience no change have about 1.3 siblings in the household. The differences are similar for girls. Girls who experience a change in household structure, but lived with both parents in the first period were 4.9 years old on average and had 1.1 siblings in the household at wave I, and those who are in a two-parent household and don't experience a change were about 6.8 years old with almost 1.3 siblings in the household. The racial composition of boys and girls in two-parent households that eventually split are also similar. In both cases, there are roughly equal percentages of black and white individuals in the subsamples, and the percentage of Hispanic individuals is relatively small. Lastly, the percentage of children in two-parent households in which their parents are married is about 86 percent for girls and nearly 90 percent for boys. 


\section{Estimation}

The main contribution of this paper is the estimation of the gender gaps in time investments in single-mother households. To estimate the gender gaps, I use individual fixed effects regressions, including interactions between a dummy for being in a single-mother household with male and female dummy variables. The gender gap is the difference in the coefficients on the male and female interactions.

$$
T_{i t}=\alpha+\beta_{M} \cdot M_{i} \cdot M O_{i t}+\beta_{F} \cdot F_{i} \cdot M O_{i t}+\beta_{3} \cdot \text { Other }_{i t}+X_{i t} \cdot \Gamma+c_{i}+\varepsilon_{i t}
$$

The left hand side variable in equation (1), $T_{i t}$, represents some measure of parental time investments that child $i$ received in wave $t$. For most specifications the investment measures are the amount of time that child $i$ spent participating in activities with his or her mother/father from the weekday/weekend twenty-four hour time diary, measured in hours. In the main specification, I report estimates for the weekday and weekend investments, as well as a total weekly investment constructed as a weighted sum of the weekday and weekend investments. I construct the total investment by summing the weekday investment multiplied by five with the weekend investment multiplied by two. For ease of reporting and because using the weekly measure better reflects the effects on total investments, I focus on reporting estimates for total investments in alternate specifications that use the hours measure. I also include estimates based on equation (1) that replace the hours measures with a dummy variable indicating whether the child had any positive investment from his or her mother/father. In that specification, the outcome of interest is equal to one when the time investment is greater than zero for the given time diary. ${ }^{20}$

The independent variables of interest are the interaction terms, where $M_{i}$ and $F_{i}$ represent male and female dummy variables, and $M O_{i t}$ represents a dummy variable indicating whether child $i$ was in a single-mother household at wave $t$. There are two other types of household structures to consider. Living in the same household as both parents is the omitted category, and Other ${ }_{i t}$ indicates whether child $i$ was in some other household type during wave $t$. The third category,

\footnotetext{
${ }^{20}$ For the weekday/weekend estimates, $T_{i t}=1$ when the weekday/weekend maternal/paternal time investment is greater than zero, and $T_{i t}=0$ otherwise. For the total investment regressions, $T_{i t}=1$ when either the weekday or the weekend maternal/paternal investment is positive.
} 
Other $_{i t}$, is constructed to make the categories mutually exclusive and comprehensive. ${ }^{21}$ I focus on estimating gender gaps in investments for those living in single-mother households, because children are more likely to live with their mother if the family is separated. Furthermore, if fathers invest relatively more in boys as they get older, not having their father present in the household could hinder development for boys, even if not for girls. $X_{i t}$ represents a vector of time-varying observable characteristics including child's age and age-squared interacted with gender, the number of biological siblings in the household, and indicators for CDS wave, presence of stepparents in or out of the household, and marital status of parents in the household. ${ }^{22}$ The gender specific age terms are important, because investments are differentially related to age by gender. ${ }^{23}$ Child level, time-constant characteristics are indicated by $c_{i}$, and $\varepsilon_{i t}$ indicates a period specific error term.

I estimate equation (1) using individual level fixed effects, so that $\hat{\beta}_{M}$ is a fixed effects estimator of investments that boys receive in single-mother households relative to those in twoparent households. Similarly, $\hat{\beta}_{F}$ is an estimator for investments that girls receive in singlemother households. The parameter of interest is the difference between the two investment levels, $\beta_{\text {Diff }}=\beta_{M}-\beta_{F}$. When $\hat{\beta}_{\text {Diff }}<0$, that suggests that boys receive relatively low levels of investments in single-mother households, and $\hat{\beta}_{\text {Diff }}>0$ suggests that boys in single-mother households are relatively well off in terms of time investments.

Because I estimate $\beta_{\text {Diff }}$ using fixed effects, it is necessary to view some boys and some girls in a single-mother household during one wave and in a two-parent household in another. The procedure explained above does not restrict the direction of the change in household structure. Those who transition from a single-mother to two-parent household contribute to the estimates in the same way as those who go from a two-parent to a single-mother household. However, we might expect these two groups to be different. Omitted characteristics and behavior can directly influence transitions, as well as the level of time investments. The ages at which the child is in

\footnotetext{
${ }^{21}$ Other $_{i t}=1$ if the child was in a single-father household, or in a household with neither parent. This makes the estimated coefficient difficult to interpret but these household structures are not the focus of this study.

${ }^{22}$ Estimates that also condition on the day of the week that the diary references are included in Tables A.1 and A.2 of the appendix. Results are not sensitive to this specification.

${ }^{23}$ In an alternate specification, I include a set of age dummy variables interacted with gender. The results are robust to this specification.
} 
each household structure is also related to the direction of the transition. If the size of the gender gap differs with age, it could lead to estimating different gaps depending on the direction of the transition. I report separate estimates for the sample of those who lived with both parents in the first period and for those who did not to examine this possible heterogeneity. In addition, I examine investment gap heterogeneity by age and race, and decompose the gaps into specific activities to determine which are the main contributors to the differential investment losses.

Lastly, I investigate differential changes in parental ratings of non-cognitive behavior around the changes in household composition. Learning more about how parental time investments factor into the generation of non-cognitive skills is a primary concern. I examine differential changes by

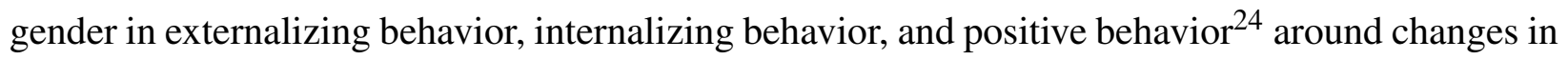
household structure. To do this, I estimate equation (1) using individual fixed effects and replacing the time investment measures with the behavioral measures. While these data are well-suited for measuring parental time investments, using parent-rated behavior measures may be problematic because parental perceptions of the child's behavior could change differentially by gender around changes in household structure.

\section{Results}

Before presenting the estimated gender gaps from the fixed effects regressions, I will briefly discuss OLS estimates of equation (1). Table 2 shows estimates of the male and female interaction terms, as well as the estimated difference between the male and female interaction terms, for maternal and paternal total, weekday, and weekend investments. Estimates in Table 2 are conditional on a set of covariates, including male and female interactions with age and age-squared. The estimated coefficient on the male interaction with single-mother household in the equation for total maternal

\footnotetext{
${ }^{24}$ Each of the three ratings is based on a series of questions asked to the child's primary caregiver. Externalizing and internalizing behavior questions ask how frequently the child exhibits some externalizing (i.e. acting out) or internalizing (i.e. inward negative) behavior and have three possible answers: not true, sometimes true, or often true. The data are coded so that higher scores mean that the child exhibits more problematic behavior. The positive behavior questions ask how like the child certain behaviors/characteristics are (e.g. cheerful, not impulsive), and are answered on a one to five scale, where one means the behavior/characteristic is not at all like the child and five means it is totally like the child. A higher score on the positive behavior rating means that the child displays less problematic behavior.
} 
investments from column 1, suggests that boys in single-mother households receive 1.24 hours per week more from their mothers, relative to children in two-parent households. Subtracting the coefficient on the female and single-mother household interaction gives the estimated gender difference in investments. Again from column 1, the estimated gender gap is 0.1 hours per week, suggesting that boys are relatively well off in terms of maternal investments. We can decompose the total difference by looking at the weekday and weekend gaps. From column 2, the estimated gap is -0.049 , meaning that boys in single-mother households received roughly 3 fewer minutes in weekday investments than girls. On the other hand, from column 3, boys in single-mother households received roughly eleven minutes more per weekend day than girls. In this case, the weekend gap outweighs the weekday gap, and the estimated total difference is positive. The estimates for paternal investments are shown in columns 4 through 6 . In column 4 we see that boys in single-mother homes have relatively large decreases in investments, compared to girls, estimated at -7.5 and -6.5 hours per week, respectively, leading to an estimated gender gap of about one hour per week. The concern with using OLS to estimate the gender gap is that it relies heavily on cross-sectional variation, but both family structure and gender are likely correlated with unobservable determinants of time investments. The fixed effects estimator is preferable because it restricts the comparison to changes in investments within individuals who underwent a change in household structure with changes in investments for children who remain in two-parent households. The remainder of the reported estimates of equation (1) are fixed effects estimates.

Table 3 reports fixed effects estimates of the gender gap in time investments based on equation (1) for maternal/paternal total, weekday, and weekend investments. The specification reported in panel A does not include any control variables, and the specification in panel B includes the full set of controls. Column 4 of panel A shows estimates for total weekly paternal investments without controls. The estimated gap in paternal investments is -1.92 , meaning that paternal investments drop by nearly 2 hours more per week for boys in single-mother homes than they do for girls. After adding controls, while the estimated coefficients on the gender/single-mother interactions change, the estimated total gap in paternal investments remains similar. For example, the estimated coefficient on the male interaction with single-mother household goes from -10.3 without controls to 
-7.3 after adding controls. Similarly, the estimated coefficient on the female interaction goes from -8.4 without controls to -4.9 with controls. In both cases, the estimates suggest that paternal investments drop for boys and girls after going to single-mother households, but the decrease is relatively large for boys. From panel B, the estimated gender difference in total weekly paternal investments is -2.36 , which is similar to the estimate from panel A, suggesting that paternal investments drop by nearly $2-1 / 2$ hours more per week for boys in single-mother homes than they do for girls. That estimate is both economically significant, as the estimated gap is more than 20 percent of average paternal investments across gender and household types during wave I, and statistically important with a standard error of 1.08. The gender difference is strongest through weekday investments, for which the estimated gap, from column 5 of panel $\mathrm{B}$, is -0.4 with a standard error of 0.15 . That equates to roughly 24 minutes per weekday and is about 35 percent of average paternal weekday investments during wave I. To put the size of that estimate in perspective, consider Figure 3 again, which graphs paternal weekday investments during the first wave of the CDS. Average paternal investments to boys and girls in two-parent households generally lie between 1 and 2 hours, depending on age. There is a slight downward trend, and the line drops below 1-1/2 hours by about age 7 for both boys and girls. The estimated difference of 24 minutes represents about twenty percent of the average paternal weekday investment in two-parent households at the lower end and 40 percent at the higher end. Although the weekday gap drives about 80 percent of the estimated total weekly gap, the gap in paternal weekend investments is also negative, -0.22 hours, but only drives about 20 percent of the gap because of it's smaller magnitude and lower weight in the makeup of the total weekly investment measure.

The difference between the OLS and fixed effects estimates for total paternal time can be explained by examining how each individual contributes to each estimator. In the OLS estimator, those who transition from two-parent to single-parent households, or vice versa, are in the omitted group (two-parent household) in one period and in a different group in another. With the fixed effects estimator, they are never in the omitted category. Girls who eventually go through a twoparent to single-mother transition have a lower baseline input than boys who make the same transition, because paternal investments to girls in two-parent households decrease as they get older. 
Since paternal investments are very low for both genders when their father is not in the household, the within-child drop in paternal investments after going from a two-parent to single-mother household is relatively large for boys. From column 3 of Table 1, boys in two-parent households that eventually split are age 4.6 and get 16.7 hours in weekly paternal investments. On the other hand, girls in the same household structure, from column 7, are of a similar age, 4.9 years old, but receive a much smaller paternal investment, 13.2 hours per week. When the average paternal investment decreases drastically to near zero for both genders after the transition to a single-mother household, there is more room for a decrease in paternal investments for boys. Another way to see this is to compare average investments for boys in two-parent households that never split with those who eventually split, 16.3 and 16.7, respectively, which are quite similar, despite the age difference in the two groups. On the other hand, girls who are always in a two-parent household receive about 15 hours per week in paternal investments, but those in a two-parent household that eventually splits only receive about 13.2. Finally, consider the similarity in the estimated change for boys, $\hat{\beta}_{M},-7.5$ hours when estimated by OLS and -7.3 when estimated by fixed effects. The difference between the fixed effects and OLS estimates of $\hat{\beta}_{\text {Diff }}$ is through a difference in the estimates on the coefficient for girls, $\hat{\beta}_{F}$, which are -6.5 and -4.9 when estimated by OLS and fixed effects, respectively.

While the boy-girl differences in paternal investments are both economically and statistically important, it is possible that single-mothers compensate for the extra losses by increasing their investments to boys relative to girls. Columns 1 - 3 of Table 3 show the estimated differences in total, weekday, and weekend maternal investments. From columns 2 and 3 of panel A, estimated weekday and weekend maternal investments are smaller for boys and girls in single-mother households. However, both weekday and weekend maternal investments are relatively low for boys, leading to estimated gaps of -0.19 for weekdays and -0.03 for weekends. From column 1 of panel A, the estimated total weekly gender difference in maternal investments is -1.4 , meaning that boys suffer larger investment losses than girls of almost 1-1/2 hours per week. Adding the full set of control variables changes the estimated coefficients on the interaction terms, but does not lead to significant changes in the estimated gaps. Column 2 of panel B shows that the estimated gender 
gap in maternal weekday investments grows slightly in magnitude to -0.207 . From column 3 of panel B, the estimated gap in weekend investments is now -0.003 . The total gap in maternal investments, from column 1 of panel $\mathrm{B}$, is about -1.1 , meaning that boys in single-mother homes receive fewer maternal investments than girls in single-mother homes, and the magnitude is similar to the estimated -1.4 hours per week from panel A. The negative estimate on the gap in total maternal investments suggests that mothers do not compensate, but instead decrease their investments to boys relative to girls. However, the standard error for the estimated difference is relatively large, 1.6, so we should not draw any strong conclusions based on that difference.

The analysis in Table 3 does not restrict the direction of the household transition, including children who go from a two-parent household to a different household type, as well as those who go from not living in a two-parent household to living with both parents. However, these two types of transitions and families could be quite different from each other. One reason that we might expect heterogeneity based on the direction of the transition is that the age that the child is in each household structure is correlated with the direction of the transition. Differential gaps by age could lead to different estimates when splitting the sample by the direction of the transition. Table 4 shows separate estimates by initial household structure. Columns 1 and 2 show estimates for total weekly investments for families that were intact in the first wave, and columns 3 and 4 show estimates for children with less than two parents in the household in the first period. From column 2, the estimated gender difference in total paternal investments for those who were in a two-parent household in the first wave is -4.2 hours per week with a standard error of 1.54 . Restricting to the subsample of individuals who were in two-parent households in wave one increases the magnitude of the estimated gap in paternal investments by almost 80 percent. However, the estimated gap in maternal investments becomes positive, 0.688 , after restricting to those in two-parent households in the first wave. The positive sign on total maternal investments suggests that mothers might compensate for the extra losses that boys suffer in paternal investments, but the estimate is noisy, and much smaller in magnitude than the loss in paternal investments. If we take these estimates at face value, then boys lose an additional 4.2 hours per week in paternal investments, about 70 percent of wave one average paternal investments, and mothers partially compensate for the loss 
with an additional 40 minutes per week. While the increase partially offsets the loss, about 17 percent of it, boys still suffer substantially larger investment losses from transitioning to a singlemother home.

Columns 3 and 4 of Table 4 display estimates when restricting to the subsample of individuals who were not in a two-parent home in the first wave. There are fewer movers in this direction and the standard errors are relatively large, but the estimates suggest that the direction of the move likely matters. For example, the estimated gap in maternal investments in the subsample who were not in two-parent homes in wave one is -3.5 hours per week. This estimate is of the opposite sign from the subsample of children who were in two-parent homes in the first wave, and relatively large in magnitude. In other words, this subsample is driving the negative estimates on total maternal investments in the full sample. The estimated gap in paternal investments is still negative, -.18 , but much smaller in magnitude. Although there appears to be some heterogeneity based on the direction of the transition, the estimates in the sample of children not in two-parent households in the first wave are based on a relatively small number of transitions and the differences are not statistically significant.

In addition to estimating differences in parental time investments, I include supplemental estimates on the probability of having a positive investment. In this specification, I replace the number of hours spent with the mother/father with a dummy variable for having any investment, and estimate the differences using linear fixed effects regressions. From column 1 of Table 5, the estimated change in the probability of receiving a nonzero maternal investment after transitioning to a single-mother household is 0.040 for boys, and 0.068 for girls, leading to an estimated gender gap of -0.028 in favor of girls. In other words, after the transition, girls see a relatively large bump in their probability of having any investment from their mothers. However, the estimate is noisy with a standard error of 0.033 . Interestingly, the sign on the weekday and weekend maternal investments estimates are different, with the estimated gap in receiving any weekday investment favoring girls, and the estimated gap in weekend investments favoring boys. For paternal investments, the estimated gap in the probability of receiving any weekday investment is -0.08 , meaning that boys receive about an 8 percentage point more drastic change in the probability of receiving a 
positive paternal investment on weekdays. The analogous weekend estimate is -0.047 . However, the estimated gap in the total weekly probability is much smaller in absolute value than both the weekday and weekend estimates, only -0.01 . That suggests that, although boys see a relatively large decrease in the probability of receiving an investment on any given day, the change in their probability of receiving an investment at some point throughout the week is similar.

Splitting the sample by initial household composition reveals heterogeneity in the gender gaps of the probability of receiving a positive paternal investment. From Panel A of Table 6, those who lived with both parents in the first wave see a relatively large decrease in the probability of receiving a positive paternal investment throughout the week, with an estimated difference of 0.065. The estimated gap when looking at weekday or weekend investments only is -0.11 in both cases, suggesting that on any given weekday or weekend day boys have an 11 percentage point larger decrease in the probability of receiving a positive paternal investment. On the other hand, the estimated gender gaps in paternal investments are positive for total, weekday, and weekend investments for the subsample that lived with less than both parents in wave I, meaning that boys in single-mother households were relatively well off by this measure. However, the estimates are noisy in that subsample with an estimated gap for the week as a whole of 0.094 and a standard error of 0.089 .

\subsection{Heterogeneity in Gender Gaps}

Next, I consider heterogeneity in investment gender gaps by age and race. Because of the strong correlation between investments and age, and differential age trends by gender and household structure, one might expect that the boy-girl investment gap in single-mother households depends on the age of the child. For example, Figures 5 and 6 show how the proportion of total parental investments that come from the father increases with age for boys in two-parents households, which suggests that paternal investments become increasingly important for boys as they get older. Figures 3 and 4 provide insight to that trend by showing that gaps arise in boy and girl investments with age, with fathers spending relatively more time with boys. Furthermore, the steep decline in maternal investments from Figures 1 and 2 means that paternal investments become increasingly 
important in the makeup of total investments for boys, but less so for girls. To compare the gender gaps across ages, I group the individuals into four age bins (0 - 5, 6 - 10, $11-15$, and 16 and over) and estimate the gap for each bin. Panel A of Table 7 shows the estimates for total maternal investments by age bin. The smallest gap, -0.6 hours per week, is in the $6-10$ year old bin. From there, the gap size increases to about -1 hour per week in the $11-15$ year old bin, and then to -2.2 hours per week in the 16 and over bin. There is some suggestive evidence that relative losses for boys increase as they get older, but the estimates are noisy, all with standard errors of 1.8 or higher.

Panel B of Table 7 shows estimates for paternal investments by age bin. A clear pattern emerges in the paternal investment gaps, with boys suffering greater investment losses with age. The smallest estimate is -0.4 hours per week for ages $0-5$, but they increase in magnitude with each age bin. The rest of the estimated gaps are -1.8 hours per week for $6-10$ year olds, -3.3 for 11 - 15 year olds, and -3.6 for the 16 and over age group with p-values of 0.12, 0.006 and 0.02 , respectively. The pattern in these estimated differences supports the idea that paternal investments become increasingly important for boys as they get older, leading to relatively large investment losses during adolescence.

I also estimate differential gaps by race, focusing on the white and black subsamples, as those two races make up more than 90 percent of the sample of children who made a transition from a two-parent to less than two-parent household. From Table 8, the estimated gender gap in total maternal investments for white children in single-mother households is -3.1 hours per week with a standard error of 2.5. The estimated differences for black children in single-mother households is -1.4 hours per week with a standard error of about 2.3. Both of the point estimates are larger in magnitude than the overall estimate, but the estimates are noisy and not statistically different from zero at any standard significance level. The estimated difference in paternal investments for white children in single-mother households is about -4 hours per week, and is strongly statistically significant with a standard error of 1.6. That estimate is similar in magnitude to the overall estimated gap for the subsample of children who were in two-parent households in the first wave. The estimate for the black subsample is about half the size, -2 hours per week, which is similar to the estimated gap across the full sample, and is less statistically significant, with a standard error of 
1.4. While all four of the estimated gaps are negative, the differences provide some evidence that the extra losses suffered by boys who are white are larger in terms of both maternal and paternal investments. Parental investments are also larger on average across the sample of white children, which could drive part of the difference. For example, the average weekly maternal investment for white children in two-parent households is about 3 hours more per week than that for black children in two-parent households (21.5 hours per week to 18.2 hours per week), and the difference in weekly paternal investments is similar (14.5 hours per week to 10.9 hours per week).

\subsection{Composition of the Investment Gaps}

Using descriptions of the time diary activities, I estimate the gender gaps by activity type to determine which activities are the most important contributors to the overall differences. Table 9 displays fixed effects estimates of equation (1) by activity category. ${ }^{25}$ Column 1 provides estimates on total maternal investments. Estimated gaps in maternal investments are positive on passive leisure (0.22 hours per week), e.g. watching television, tending to needs ( 0.1 hours per week), and childcare ( 0.18 hours per week), meaning that mothers increase time with boys relative to girls in those activities after transitioning to a single-mother household. On the other hand, maternal investments of active leisure decrease substantially more for boys in single-mother households. The estimate of -0.85 hours per week in active leisure is the largest in magnitude of any activity. Boys also experience relatively large reductions in paternal investments in leisure, -0.72 and -0.75 hours per week in passive and active leisure, respectively. In general, boys see a much larger drop-off in leisure activity with their parents than girls do after transitioning to a single-mother household. The rest of the estimates for paternal investments displayed in Table 9 are also negative, but generally of a smaller magnitude than the estimates for leisure activity. The next two largest are the differences in tending to needs, -0.48 hours per week, and entertainment, -0.21 hours per week.

\footnotetext{
${ }^{25}$ This is not a comprehensive set of the activities, but they account for the majority of the differences. The estimates for the gaps in paternal investments displayed in Table 9 add up to a little more than the total difference, -2.5 hours per week compared to -2.3 . The displayed estimates for maternal investments add up to about -0.7 , which can account for $63 \%$ of the total gap.
} 


\subsection{Household Structure and Child Behavior}

One reason for analyzing gender gaps in the relationship between household structure and parental investments is to assess the possibility that changes in investment levels contribute to non-cognitive skill formation, explaining some of the differences we see in outcomes between boys and girls, e.g. behavior and educational attainment. If the documented gaps in time investment losses from transitioning to single-mother households contribute to contemporaneous behavioral issues, then we might expect to see changes in behavior that match the differential investment losses. In other words, if the additional investment decreases that boys suffer is bad for their behavior, then we would expect that to show up in measures of their behavior. I estimate the gender differential changes in behavior from transitioning to single-mother households by replacing the outcome variables in equation (1), parental time investments, with measures of child behavior. One major weakness of this exercise is that the behavioral measures, taken from the CDS, are parent-reported. This is problematic because parental perceptions of their child's behavior could change differentially by gender around household structure transitions. Nonetheless, I show results from the analysis to demonstrate the concept.

Table 10 shows results from fixed effects estimation of equation (1), replacing the parental investment outcomes with three parent-rated behavior measures: externalizing behavior, internalizing behavior, and positive behavior. Each of the ratings are the result of a sequence of questions that the parent answers about the child. ${ }^{26}$ Each of the questions related to externalizing/internalizing behavior are answered on a one through three scale, and the questions for positive behavior are on a one through five scale. Parent responses to the questions were summed and the totals were standardized within each wave. Higher scores in externalizing and internalizing behavior represent more problematic behavior, but a higher score on the positive behaviors measure represents less problematic behavior. Interestingly, The estimated coefficient on the male interaction with single-mother household in the equation for externalizing behavior is negative, -0.11 , meaning that parents rate their boys as displaying less externalizing behavior following the transition. On the other hand, the coefficient on the female interaction term is positive, 0.16 , meaning that parents

\footnotetext{
${ }^{26}$ Due to minor differences in the questions across the three waves, I use the raw responses to standardize the set of questions contributing to each behavioral measure
} 
report that girls act out more frequently following the transition. The externalizing behavior ratings for boys become much more favorable following the transition to a single-mother household, relative to girls, and the estimated gap in changes in externalizing behavior, from column 1 , is -0.27 standard deviations. The result is also statistically significant, with a p-value of 0.02. Apparently, the change in household structure is not leading to more externalizing behavior for boys, according to the parent-rated measure, like we might have expected based on the additional investment losses. The estimated gaps in the other two measures are much smaller in magnitude, -0.007 for internalizing behavior and 0.11 for positive behavior. The estimated gap in externalizing behavior is surprising, but this gap should be estimated using measures that are not based on parent ratings in future work.

\section{Conclusion}

Determining the mechanisms that lead to gender gaps in non-cognitive skills is largely an open question [Bertrand and Pan, 2013, Jacob, 2002, Autor et al., 2016b]. Gender gaps in non-cognitive skills among adolescents could arise for several reasons, including gender differences in returns to and levels of inputs in single-mother and two-parent households. Disentangling the contributions of mechanisms leading to non-cognitive differences is complicated by the presence of many inputs, most of which are correlated with household structure, and difficult to measure and interpret. Using time diary data from the Child Development Supplement to the PSID, I obtain direct measures of parental time investments and estimate gender differences in time investments around changes in household composition. Although both boys and girls see significant reductions in parental investments when living in single-mother homes, boys experience larger decreases in paternal investments of about 2.3 hours per week, more than 20 percent of the average paternal investment in the first wave of the CDS. The additional loss in paternal investments is strongest through weekday investments, 24 minutes per weekday, which explains about 80 percent of the total loss. There is no strong evidence that mothers compensate for the extra loss by increasing investments to boys following a change in household structure, relative to girls. Additional losses for boys are generally increasing with age, with the estimated gap in total paternal investments over 3.3 hours per week 
for boys during adolescence. This is especially important, because non-cognitive skills continue to develop through adolescence [Heckman and Mosso, 2014]. Differences in leisure activities account for about 60 percent of the gender gap in paternal investment losses.

Finding differential investment losses by gender suggests that living in a single-mother household could have a large negative impact on the quantity of investments that boys receive relative to girls. All of this evidence considered together with existing research suggests that time investments are another potential mechanism that may help explain the non-cognitive skill gender gap, specifically for those in single-mother households. However, using parent-reported ratings of externalizing and positive behavior from the CDS, I find that parents rate their girls as having higher levels of externalizing behavior and lower levels of positive behavior when in single-mother households, relative to boys. Future research should consider a more direct link between time investments and outcomes, focusing on measures of non-cognitive skills that are not based on parent ratings. 
Compliance with Ethical Standards:

Funding: This study was funded by a Pre-Doctoral Training Grant from the Institute of Education

Sciences, U.S. Department of Education (Grant \#R305B090011) to Michigan State University.

\section{References}

[Autor et al., 2016a] Autor, D., Figlio, D., Karbownik, K., Roth, J., and Wasserman, M. (2016a). Family disadvantage and the gender gap in behavioral and educational outcomes. National Bureau of Economic Research (No. w22267).

[Autor et al., 2016b] Autor, D., Figlio, D., Karbownik, K., Roth, J., and Wasserman, M. (2016b). School quality and the gender gap in educational achievement. The American Economic Review Papers and Proceedings, 106(5):289-295.

[Baker and Milligan, 2013] Baker, M. and Milligan, K. (2013). Boy-girl differences in parental time investments: Evidence from three countries. National Bureau of Economic Research (No. w18893).

[Becker et al., 2010] Becker, G. S., Hubbard, W. H., and Murphy, K. M. (2010). Explaining the worldwide boom in higher education of women. Journal of Human Capital, 4(3):203-241.

[Bertrand and Pan, 2013] Bertrand, M. and Pan, J. (2013). The trouble with boys: Social influences and the gender gap in disruptive behavior. American Economic Journal: Applied Economics, 5(1):32-64.

[Chetty and Hendren, 2016] Chetty, R. and Hendren, N. (2016). The impacts of neighborhoods on intergenerational mobility i: Childhood exposure effects. National Bureau of Economic Research (No. w23001).

[Chetty et al., 2016a] Chetty, R., Hendren, N., and Katz, L. F. (2016a). The effects of exposure to better neighborhoods on children: New evidence from the moving to opportunity experiment. The American Economic Review, 106(4):855-902. 
[Chetty et al., 2016b] Chetty, R., Hendren, N., Lin, F., Majerovitz, J., and Scuderi, B. (2016b). Childhood environment and gender gaps in adulthood. The American Economic Review Papers and Proceedings, 106(5):282-288.

[Cunha and Heckman, 2008] Cunha, F. and Heckman, J. J. (2008). Formulating, identifying and estimating the technology of cognitive and noncognitive skill formation. Journal of human resources, 43(4):738-782.

[Dahl and Moretti, 2008] Dahl, G. B. and Moretti, E. (2008). The demand for sons. The Review of Economic Studies, 75(4):1085-1120.

[Del Boca and Mancini, 2013] Del Boca, D. and Mancini, A. L. (2013). Parental time and child outcomes: Does gender matter? Bank of Italy Occasional Paper, (187).

[Del Boca et al., 2017] Del Boca, D., Monfardini, C., and Nicoletti, C. (2017). Parental and child time investments and the cognitive development of adolescents. Journal of Labor Economics, 35(2):565-608.

[Deming, 2016] Deming, D. J. (2016). The growing importance of social skills in the labor market. National Bureau of Economic Research (No. w21473).

[Fortin et al., 2015] Fortin, N. M., Oreopoulos, P., and Phipps, S. (2015). Leaving boys behind gender disparities in high academic achievement. Journal of Human Resources, 50(3):549579.

[Goldin et al., 2006] Goldin, C., Katz, L. F., and Kuziemko, I. (2006). The homecoming of american college women: The reversal of the college gender gap. The Journal of Economic Perspectives, 20(4):133-133.

[Guryan et al., 2008] Guryan, J., Hurst, E., and Kearney, M. (2008). Parental education and parental time with children. Journal of Economic Perspectives, 22(3). 
[Heckman et al., 2013] Heckman, J., Pinto, R., and Savelyev, P. (2013). Understanding the mechanisms through which an influential early childhood program boosted adult outcomes. The American Economic Review, 103(6):2052-2086.

[Heckman and Mosso, 2014] Heckman, J. J. and Mosso, S. (2014). The economics of human development and social mobility. National Bureau of Economic Research (No. w19925).

[Heckman et al., 2006] Heckman, J. J., Stixrud, J., and Urzua, S. (2006). The effects of cognitive and noncognitive abilities on labor market outcomes and social behavior. Journal of Labor economics, 24(3):411-482.

[Jacob, 2002] Jacob, B. A. (2002). Where the boys aren't: Non-cognitive skills, returns to school and the gender gap in higher education. Economics of Education Review, 21(6):589-598.

[Kristoffersen et al., 2015] Kristoffersen, J. H., Obel, C., and Smith, N. (2015). Gender differences in behavioral problems and school outcomes. Journal of Economic Behavior \& Organization, 115:75-93.

[Lundberg et al., 2007] Lundberg, S., Pabilonia, S. W., and Ward-Batts, J. (2007). Time allocation of parents and investments in sons and daughters. Unpublished paper.

[Owens, 2016] Owens, J. (2016). Early childhood behavior problems and the gender gap in educational attainment in the united states. Sociology of Education, 89(3):236-258.

[Panel Study of Income Dynamics, 2014] Panel Study of Income Dynamics, p. u. d. (2014). Produced and distributed by the Survey Research Center, Institute for Social Research, University of Michigan, Ann Arbor, MI.

[Price, 2008] Price, J. (2008). Parent-child quality time does birth order matter? Journal of Human Resources, 43(1):240-265.

[Yeung et al., 2001] Yeung, W. J., Sandberg, J. F., Davis-Kean, P. E., and Hofferth, S. L. (2001). Children's time with fathers in intact families. Journal of Marriage and Family, 63(1):136-154. 
Figure 1

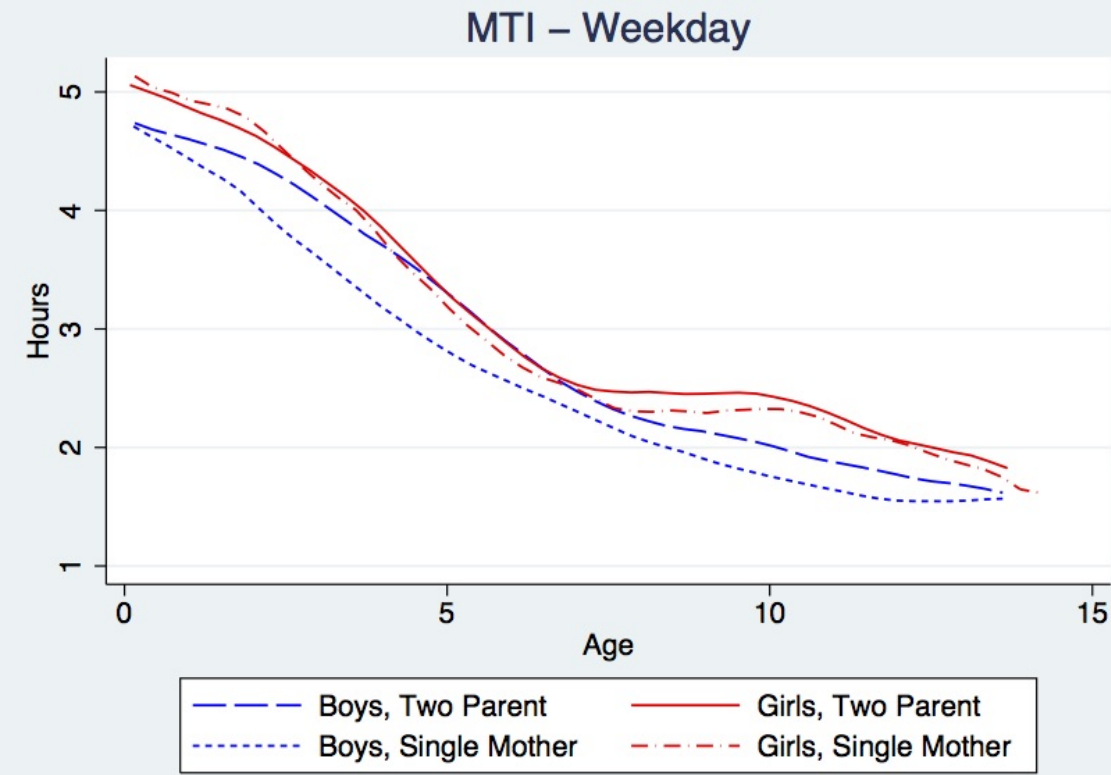

Figure 2

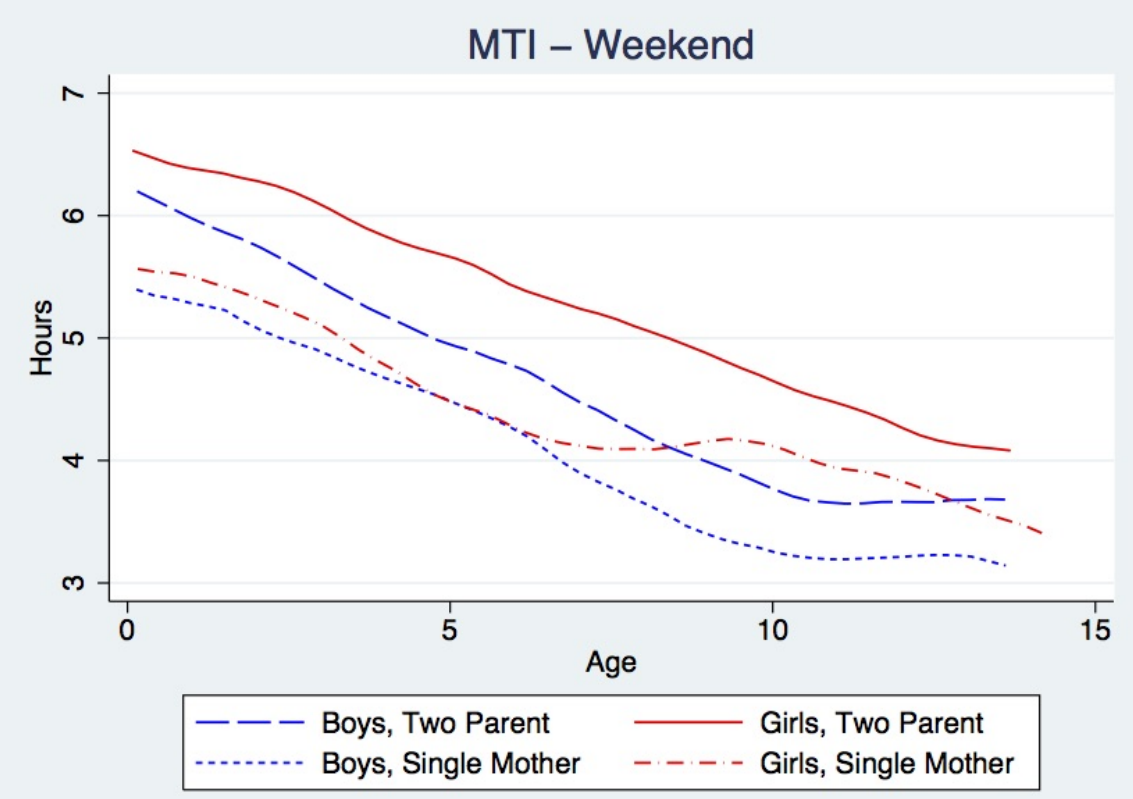


Figure 3

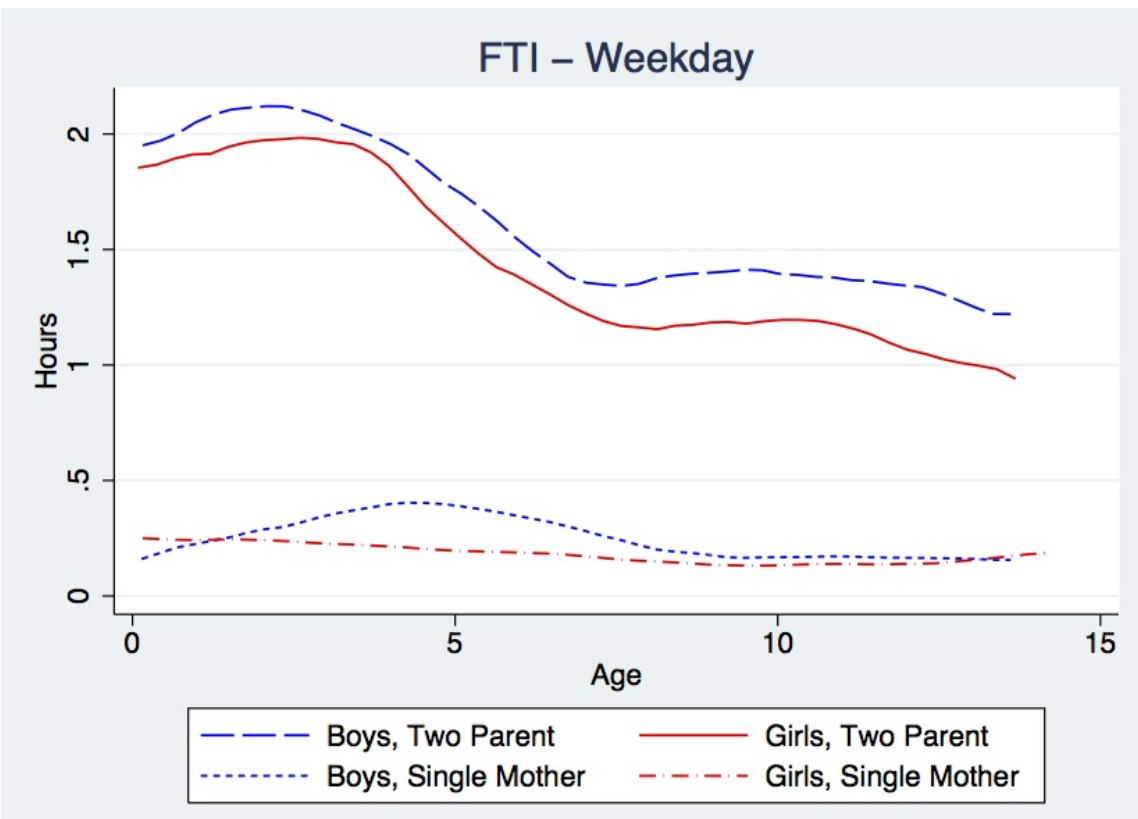

Figure 4

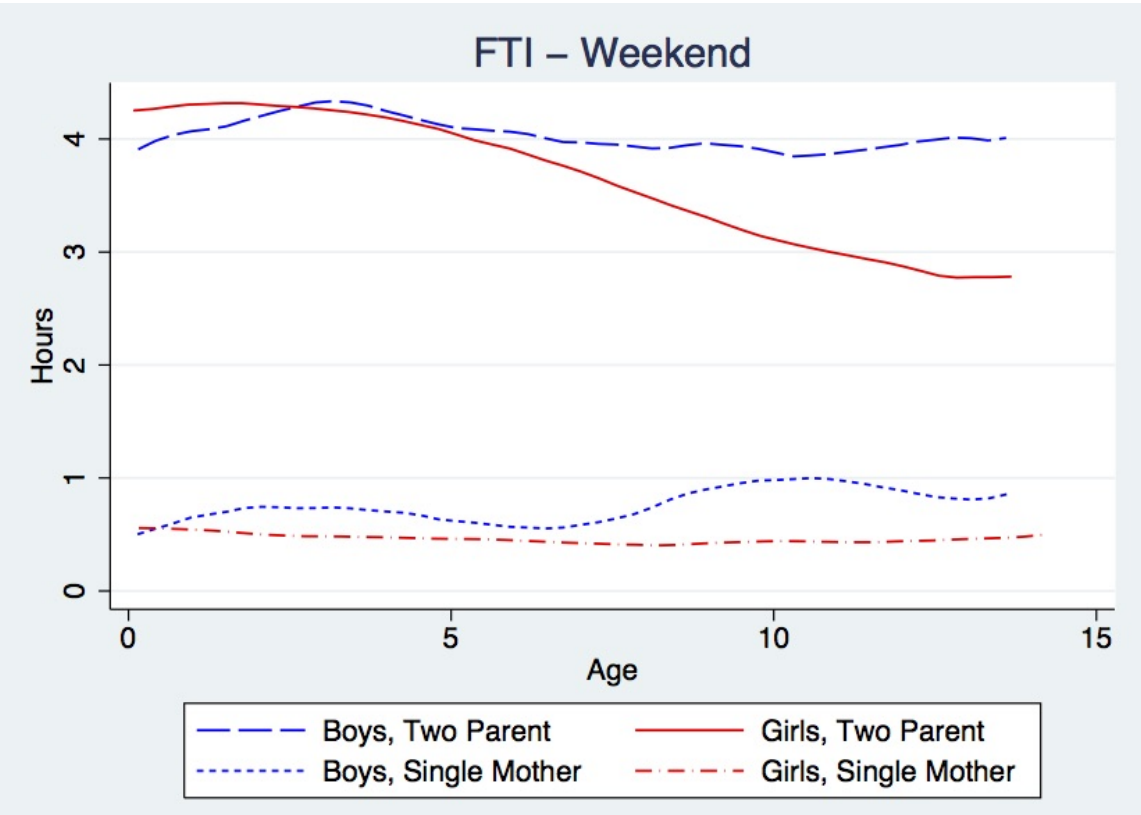


Figure 5

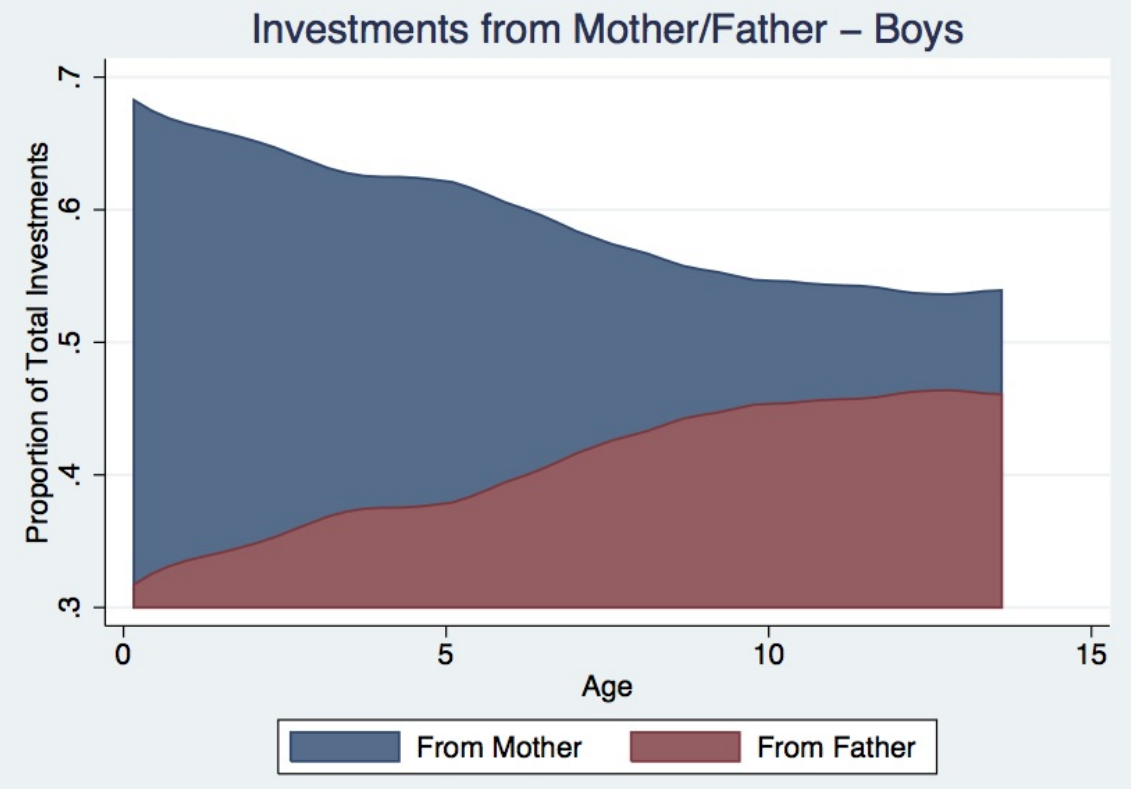

Figure 6

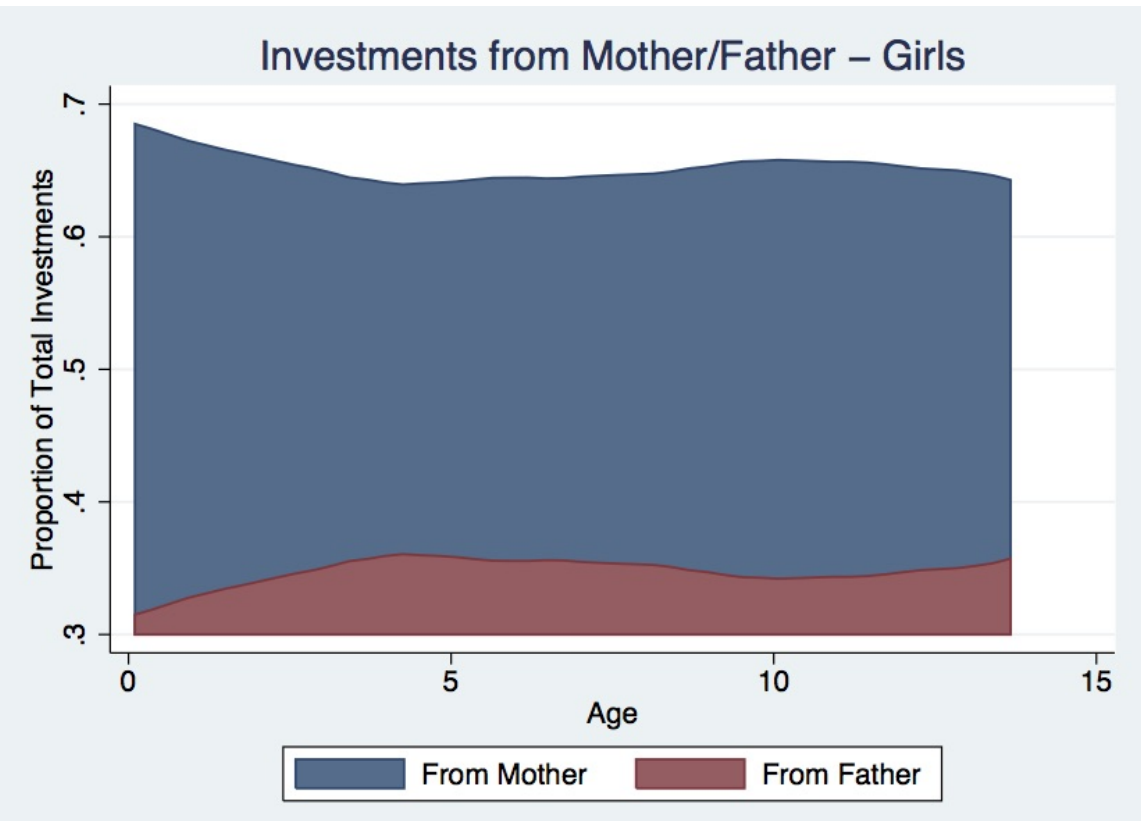


Table 1: Wave I Summary by Gender \& Household Structure

\begin{tabular}{|c|c|c|c|c|c|c|c|c|}
\hline & \multicolumn{2}{|c|}{ Boys-No Change } & \multicolumn{2}{|c|}{ Boys-Change } & \multicolumn{2}{|c|}{ Girls-No Change } & \multicolumn{2}{|c|}{ Girls-Change } \\
\hline & $\begin{array}{c}\text { Both } \\
{[1]}\end{array}$ & $\begin{array}{l}<2 \\
{[2]}\end{array}$ & $\begin{array}{c}\text { Both } \\
{[3]}\end{array}$ & $\begin{array}{l}<2 \\
{[4]}\end{array}$ & $\begin{array}{c}\text { Both } \\
{[5]}\end{array}$ & $\begin{array}{l}<2 \\
{[6]}\end{array}$ & $\begin{array}{c}\text { Both } \\
{[7]}\end{array}$ & $\begin{array}{l}<2 \\
{[8]}\end{array}$ \\
\hline \multicolumn{9}{|c|}{ Mother's Investments } \\
\hline Total & $\begin{array}{c}24.802 \\
(15.206)\end{array}$ & $\begin{array}{c}18.847 \\
(15.226)\end{array}$ & $\begin{array}{c}25.568 \\
(15.264)\end{array}$ & $\begin{array}{c}18.116 \\
(17.029)\end{array}$ & $\begin{array}{c}26.608 \\
(15.486)\end{array}$ & $\begin{array}{c}21.694 \\
(19.368)\end{array}$ & $\begin{array}{c}27.455 \\
(15.495)\end{array}$ & $\begin{array}{l}21.946 \\
(18.872)\end{array}$ \\
\hline Weekday & $\begin{array}{l}3.073 \\
(2.415)\end{array}$ & $\begin{array}{c}2.289 \\
(2.291)\end{array}$ & $\begin{array}{l}3.100 \\
(2.372)\end{array}$ & $\begin{array}{l}2.238 \\
(2.554)\end{array}$ & $\begin{array}{l}3.199 \\
(2.477)\end{array}$ & $\begin{array}{l}2.705 \\
(3.074)\end{array}$ & $\begin{array}{l}3.301 \\
(2.566)\end{array}$ & $\begin{array}{c}2.803 \\
(2.606)\end{array}$ \\
\hline Weekend & $\begin{array}{c}4.719 \\
(3.206)\end{array}$ & $\begin{array}{c}3.701 \\
(3.266)\end{array}$ & $\begin{array}{c}5.035 \\
(3.156)\end{array}$ & $\begin{array}{c}3.464 \\
(3.368)\end{array}$ & $\begin{array}{l}5.306 \\
(3.192)\end{array}$ & $\begin{array}{l}4.085 \\
(3.504)\end{array}$ & $\begin{array}{l}5.476 \\
(3.195)\end{array}$ & $\begin{array}{c}3.964 \\
(3.681)\end{array}$ \\
\hline \multicolumn{9}{|c|}{ Father's Investments } \\
\hline Total & $\begin{array}{c}16.371 \\
(11.397)\end{array}$ & $\begin{array}{c}3.531 \\
(7.945)\end{array}$ & $\begin{array}{c}16.771 \\
(13.147)\end{array}$ & $\begin{array}{l}5.056 \\
(9.518)\end{array}$ & $\begin{array}{c}15.061 \\
(11.440)\end{array}$ & $\begin{array}{l}2.218 \\
(6.621)\end{array}$ & $\begin{array}{c}13.246 \\
(10.919)\end{array}$ & $\begin{array}{c}5.160 \\
(8.650)\end{array}$ \\
\hline Weekday & $\begin{array}{c}1.618 \\
(1.615)\end{array}$ & $\begin{array}{c}0.351 \\
(1.047)\end{array}$ & $\begin{array}{c}1.872 \\
(2.125)\end{array}$ & $\begin{array}{c}0.498 \\
(1.269)\end{array}$ & $\begin{array}{c}1.493 \\
(1.712)\end{array}$ & $\begin{array}{c}0.241 \\
(0.927)\end{array}$ & $\begin{array}{c}1.382 \\
(1.697)\end{array}$ & $\begin{array}{c}0.586 \\
(1.123)\end{array}$ \\
\hline Weekend & $\begin{array}{c}4.141 \\
(3.284)\end{array}$ & $\begin{array}{c}0.887 \\
(2.139)\end{array}$ & $\begin{array}{c}3.705 \\
(3.001)\end{array}$ & $\begin{array}{c}1.284 \\
(2.717)\end{array}$ & $\begin{array}{c}3.797 \\
(3.158)\end{array}$ & $\begin{array}{c}0.506 \\
(1.686)\end{array}$ & $\begin{array}{c}3.167 \\
(2.910)\end{array}$ & $\begin{array}{l}1.116 \\
(2.112)\end{array}$ \\
\hline Age & $\begin{array}{c}6.533 \\
(3.850)\end{array}$ & $\begin{array}{c}7.288 \\
(3.626)\end{array}$ & $\begin{array}{c}4.617 \\
(3.149)\end{array}$ & $\begin{array}{c}6.283 \\
(3.214)\end{array}$ & $\begin{array}{c}6.848 \\
(3.847)\end{array}$ & $\begin{array}{l}7.366 \\
(3.774)\end{array}$ & $\begin{array}{c}4.931 \\
(3.430)\end{array}$ & $\begin{array}{c}5.540 \\
(3.429)\end{array}$ \\
\hline $\begin{array}{l}\text { \# Bio Sibs } \\
\text { In HH }\end{array}$ & $\begin{array}{c}1.309 \\
(1.102)\end{array}$ & $\begin{array}{c}1.191 \\
(1.145)\end{array}$ & $\begin{array}{c}1.071 \\
(0.968)\end{array}$ & $\begin{array}{l}1.116 \\
(1.011)\end{array}$ & $\begin{array}{c}1.272 \\
(0.983)\end{array}$ & $\begin{array}{c}1.163 \\
(1.074)\end{array}$ & $\begin{array}{l}1.138 \\
(1.094)\end{array}$ & $\begin{array}{c}1.000 \\
(1.035)\end{array}$ \\
\hline White & 0.630 & 0.257 & 0.490 & 0.279 & 0.672 & 0.258 & 0.478 & 0.292 \\
\hline Black & 0.219 & 0.646 & 0.471 & 0.581 & 0.164 & 0.653 & 0.434 & 0.597 \\
\hline Hispanic & 0.094 & 0.047 & 0.006 & 0.093 & 0.106 & 0.036 & 0.038 & 0.028 \\
\hline \multicolumn{9}{|l|}{ Stepmother } \\
\hline$\overline{\text { In HH }}$ & & 0.036 & & 0.035 & & 0.014 & & 0.028 \\
\hline Out of HH & & 0.090 & & 0.105 & & 0.093 & & 0.042 \\
\hline \multicolumn{9}{|l|}{ Stepfather } \\
\hline$\overline{\text { In HH }}$ & & 0.126 & & 0.151 & & 0.127 & & 0.083 \\
\hline Out of HH & & 0.032 & & 0.023 & & 0.043 & & 0.083 \\
\hline $\begin{array}{l}\text { Parents in HH } \\
\text { and Married }\end{array}$ & 0.968 & & 0.897 & & 0.968 & & 0.862 & \\
\hline Observations & 754 & 444 & 155 & 86 & 720 & 418 & 159 & 72 \\
\hline $\begin{array}{l}\text { *Notes: This tab } \\
\text { Columns labelec } \\
\text { the sample, and } \\
\text { structure. Colum } \\
\text { the household du } \\
\text { parents in the ho }\end{array}$ & $\begin{array}{l}\text { e display: } \\
\text { No Chan }\end{array}$ & $\begin{array}{l}\text { verages by } \\
\text { contain } 1\end{array}$ & $\begin{array}{l}\text { ender an } \\
\text { nbers fo }\end{array}$ & $\begin{array}{l}\text { lousehol } \\
\text { hildren v }\end{array}$ & $\begin{array}{l}\text { pe with } \\
\text { have } n\end{array}$ & $\begin{array}{l}\text { ergo son } \\
\text { th biolog } \\
\text { ess than } t\end{array}$ & $\begin{array}{c}\text { change } 11 \\
\text { 1/adoptiv } \\
\text { biologic }\end{array}$ & $\begin{array}{l}\text { entheses. } \\
\text { ucture in } \\
\text { ousehold } \\
\text { arents in } \\
\text { adoptive }\end{array}$ \\
\hline
\end{tabular}


Table 2: OLS Estimates of Gender Gaps in Time Investments

\begin{tabular}{|c|c|c|c|c|c|c|}
\hline & \multicolumn{3}{|c|}{ Mother } & \multicolumn{3}{|c|}{ Father } \\
\hline & $\begin{array}{c}\text { Total } \\
{[1]}\end{array}$ & $\begin{array}{c}\text { Weekday } \\
\text { [2] }\end{array}$ & $\begin{array}{c}\text { Weekend } \\
{[3]}\end{array}$ & $\begin{array}{c}\text { Total } \\
{[4]}\end{array}$ & $\begin{array}{c}\text { Weekday } \\
{[5]}\end{array}$ & $\begin{array}{c}\text { Weekend } \\
{[6]}\end{array}$ \\
\hline \multicolumn{7}{|c|}{ Single Mother HH X } \\
\hline Male & $\begin{array}{c}1.243 \\
(0.963)\end{array}$ & $\begin{array}{c}0.009 \\
(0.158)\end{array}$ & $\begin{array}{c}0.620 \\
(0.214)\end{array}$ & $\begin{array}{l}-7.567 \\
(0.743)\end{array}$ & $\begin{array}{l}-0.774 \\
(0.102)\end{array}$ & $\begin{array}{l}-1.791 \\
(0.209)\end{array}$ \\
\hline Female & $\begin{array}{c}1.139 \\
(1.001)\end{array}$ & $\begin{array}{c}0.058 \\
(0.163)\end{array}$ & $\begin{array}{c}0.430 \\
(0.221)\end{array}$ & $\begin{array}{l}-6.548 \\
(0.725)\end{array}$ & $\begin{array}{l}-0.699 \\
(0.099)\end{array}$ & $\begin{array}{l}-1.489 \\
(0.209)\end{array}$ \\
\hline Other & $\begin{array}{l}-11.513 \\
(0.999)\end{array}$ & $\begin{array}{l}-1.537 \\
(0.159)\end{array}$ & $\begin{array}{l}-1.881 \\
(0.229)\end{array}$ & $\begin{array}{l}-2.069 \\
(0.936)\end{array}$ & $\begin{array}{l}-0.135 \\
(0.127)\end{array}$ & $\begin{array}{l}-0.607 \\
(0.238)\end{array}$ \\
\hline $\begin{array}{l}\text { Male - Female } \\
\text { (Standard Error) }\end{array}$ & $\begin{array}{c}0.103 \\
(0.699)\end{array}$ & $\begin{array}{l}-0.049 \\
(0.106)\end{array}$ & $\begin{array}{c}0.190 \\
(0.164)\end{array}$ & $\begin{array}{l}-1.019 \\
(0.441)\end{array}$ & $\begin{array}{c}-0.076 \\
(0.0596)\end{array}$ & $\begin{array}{c}-0.302 \\
(0.126)\end{array}$ \\
\hline Observations & 6,699 & 6,786 & 6,726 & 6,699 & 6,786 & 6,726 \\
\hline R-squared & 0.280 & 0.233 & 0.163 & 0.269 & 0.157 & 0.229 \\
\hline
\end{tabular}

*Notes: This table displays estimates from OLS regressions of time investments on child gender interacted with a dummy for being in a single-mother household. The omitted category is a household with both biological parents present. The fourth row displays the difference in the male and female interaction coefficients. Each regression includes controls for the number of biological siblings in the household, CDS wave, a marriage indicator for parents in the same household, dummy variables for having stepparents in/out of the household, gender interactions with age and age-squared, and a male dummy variable. Standard errors are in parentheses and clustered by individual. 
Table 3: Fixed Effects Estimates of Gender Gaps in Time Investments

Panel A: No Controls

\begin{tabular}{lcccccc}
\hline \hline & $\begin{array}{c}\text { Total } \\
{[1]}\end{array}$ & $\begin{array}{c}\text { Mother } \\
\text { Weekday } \\
{[2]}\end{array}$ & $\begin{array}{c}\text { Weekend } \\
{[3]}\end{array}$ & $\begin{array}{c}\text { Total } \\
{[4]}\end{array}$ & $\begin{array}{c}\text { Father } \\
\text { Weekday } \\
{[5]}\end{array}$ & $\begin{array}{c}\text { Weekend } \\
{[6]}\end{array}$ \\
\hline Single Mother HH X & & & & & & \\
\cline { 1 - 3 } & -5.550 & -0.707 & -0.905 & -10.346 & -1.222 & -2.077 \\
& $(1.229)$ & $(0.186)$ & $(0.266)$ & $(0.933)$ & $(0.131)$ & $(0.232)$ \\
Female & -4.146 & -0.509 & -0.872 & -8.425 & -0.839 & -2.032 \\
& $(1.388)$ & $(0.209)$ & $(0.302)$ & $(0.767)$ & $(0.114)$ & $(0.200)$ \\
Other & & & & & & \\
& -15.549 & -2.023 & -2.611 & -6.057 & -0.711 & -1.291 \\
Male - Female & $(1.451)$ & $(0.203)$ & $(0.332)$ & $(1.116)$ & $(0.151)$ & $(0.301)$ \\
(Standard Error) & -1.405 & -0.198 & -0.033 & -1.921 & -0.383 & -0.044 \\
& $(1.799)$ & $(0.270)$ & $(0.390)$ & $(1.166)$ & $(0.167)$ & $(0.297)$ \\
Observations & & & & & & \\
R-squared & 6,699 & 6,786 & 6,726 & 6,699 & 6,786 & 6,726 \\
Individuals & 0.031 & 0.022 & 0.019 & 0.061 & 0.037 & 0.041 \\
\hline & 3,283 & 3,308 & 3,287 & 3,283 & 3,308 & 3,287 \\
\hline
\end{tabular}

Panel B: With Controls

\begin{tabular}{|c|c|c|c|c|c|c|}
\hline & \multicolumn{3}{|c|}{ Mother } & \multicolumn{3}{|c|}{ Father } \\
\hline & $\begin{array}{c}\text { Total } \\
{[1]}\end{array}$ & $\begin{array}{c}\text { Weekday } \\
{[2]}\end{array}$ & $\begin{array}{c}\text { Weekend } \\
{[3]}\end{array}$ & $\begin{array}{c}\text { Total } \\
{[4]}\end{array}$ & $\begin{array}{c}\text { Weekday } \\
{[5]}\end{array}$ & $\begin{array}{c}\text { Weekend } \\
{[6]}\end{array}$ \\
\hline \multicolumn{7}{|c|}{ Single Mother HH X } \\
\hline Male & $\begin{array}{c}1.273 \\
(1.713)\end{array}$ & $\begin{array}{c}0.007 \\
(0.274)\end{array}$ & $\begin{array}{c}0.558 \\
(0.358)\end{array}$ & $\begin{array}{l}-7.306 \\
(1.235)\end{array}$ & $\begin{array}{l}-0.903 \\
(0.173)\end{array}$ & $\begin{array}{l}-1.332 \\
(0.318)\end{array}$ \\
\hline Female & $\begin{array}{c}2.442 \\
(1.863)\end{array}$ & $\begin{array}{c}0.214 \\
(0.281)\end{array}$ & $\begin{array}{c}0.562 \\
(0.396)\end{array}$ & $\begin{array}{l}-4.941 \\
(1.135)\end{array}$ & $\begin{array}{l}-0.503 \\
(0.159)\end{array}$ & $\begin{array}{l}-1.105 \\
(0.312)\end{array}$ \\
\hline Other & $\begin{array}{l}-7.433 \\
(1.948)\end{array}$ & $\begin{array}{l}-1.036 \\
(0.296)\end{array}$ & $\begin{array}{l}-1.109 \\
(0.409)\end{array}$ & $\begin{array}{l}-2.260 \\
(1.365)\end{array}$ & $\begin{array}{l}-0.342 \\
(0.191)\end{array}$ & $\begin{array}{l}-0.314 \\
(0.354)\end{array}$ \\
\hline $\begin{array}{l}\text { Male - Female } \\
\text { (Standard Error) }\end{array}$ & $\begin{array}{l}-1.169 \\
(1.612)\end{array}$ & $\begin{array}{l}-0.207 \\
(0.243)\end{array}$ & $\begin{array}{l}-0.003 \\
(0.372)\end{array}$ & $\begin{array}{l}-2.364 \\
(1.084)\end{array}$ & $\begin{array}{l}-0.400 \\
(0.158)\end{array}$ & $\begin{array}{l}-0.227 \\
(0.289)\end{array}$ \\
\hline Observations & 6,699 & 6,786 & 6,726 & 6,699 & 6,786 & 6,726 \\
\hline R-squared & 0.260 & 0.226 & 0.136 & 0.118 & 0.070 & 0.094 \\
\hline Individuals & 3,283 & 3,308 & 3,287 & 3,283 & 3,308 & 3,287 \\
\hline
\end{tabular}

*Notes: This table displays estimates from fixed effects regressions of time investments on child gender interacted with a dummy for being in a single-mother household. The omitted category is a household with both biological parents present. The fourth row of each panel displays the difference in the male and female interaction coefficients. Regressions in Panel A do not use any control variables. Each regression in Panel B includes controls for the number of biological siblings in the household, CDS wave, a marriage indicator for parents in the same household, dummy variables for having stepparents in/out of the household, and gender interactions with age and age-squared. Standard errors are in parentheses and clustered by individual. 
Table 4: Gender Gaps in Investments by Initial HH Structure

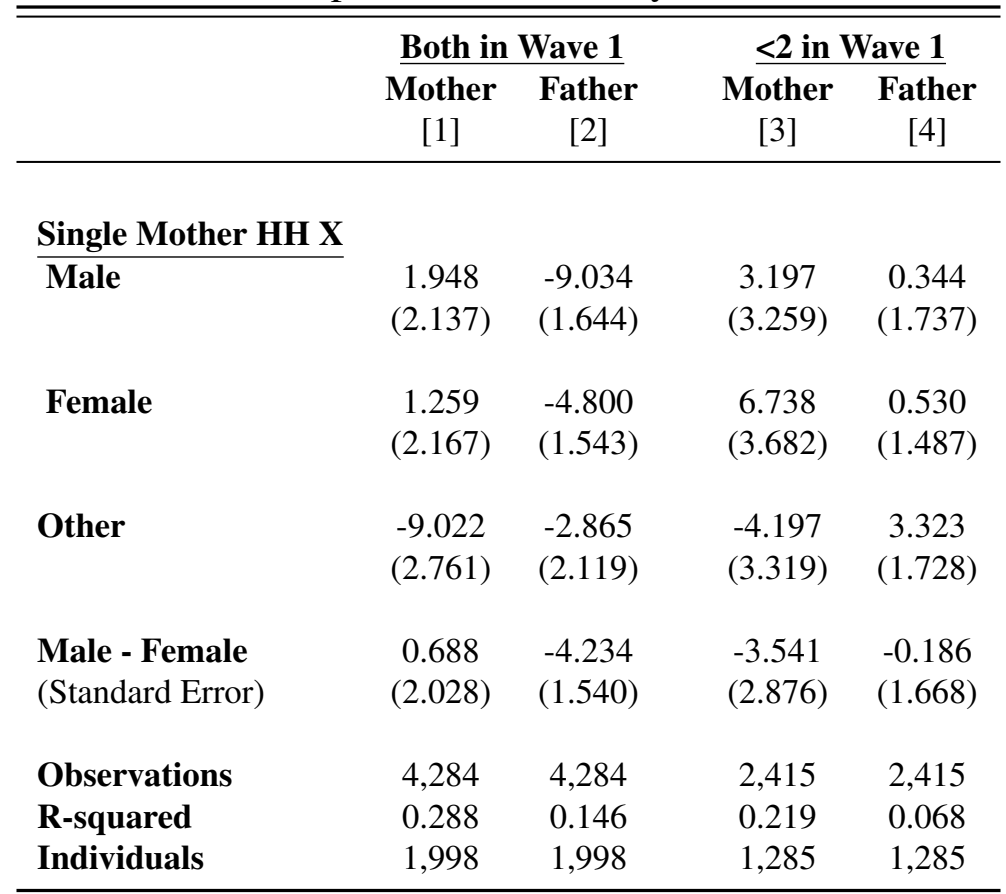

*Notes: This table displays estimates from fixed effects regressions of total weekly time investments on child gender interacted with a dummy for being in a single-mother household. The omitted category is a household with both biological parents present. Columns 1 and 2 restrict to the sample of children who were in a two-parent household in the first wave, and columns 3 and 4 restrict to those who were not living with both parents in the first wave. The fourth row displays the difference in the male and female interaction coefficients. Each regression controls for the number of biological siblings in the household, CDS wave, a marriage indicator for parents in the same household, dummy variables for having stepparents in/out of the household, and gender interactions with age and age-squared. Standard errors are in parentheses and clustered by individual. 
Table 5: FE Gender Gaps in Probability of PTI $>0$

\begin{tabular}{|c|c|c|c|c|c|c|}
\hline & \multicolumn{3}{|c|}{ Mother } & \multicolumn{3}{|c|}{ Father } \\
\hline & $\begin{array}{c}\text { Total } \\
{[1]} \\
\end{array}$ & $\begin{array}{c}\text { Weekday } \\
{[2]}\end{array}$ & $\begin{array}{c}\text { Weekend } \\
{[3]}\end{array}$ & $\begin{array}{c}\text { Total } \\
{[4]} \\
\end{array}$ & $\begin{array}{c}\text { Weekday } \\
{[5]}\end{array}$ & $\begin{array}{c}\text { Weekend } \\
{[6]}\end{array}$ \\
\hline \multicolumn{7}{|c|}{ Single Mother HH X } \\
\hline Male & $\begin{array}{c}0.040 \\
(0.032)\end{array}$ & $\begin{array}{c}0.047 \\
(0.043)\end{array}$ & $\begin{array}{c}0.055 \\
(0.044)\end{array}$ & $\begin{array}{l}-0.419 \\
(0.054)\end{array}$ & $\begin{array}{l}-0.377 \\
(0.054)\end{array}$ & $\begin{array}{l}-0.331 \\
(0.054)\end{array}$ \\
\hline Female & $\begin{array}{c}0.068 \\
(0.033)\end{array}$ & $\begin{array}{c}0.107 \\
(0.044)\end{array}$ & $\begin{array}{c}0.041 \\
(0.044)\end{array}$ & $\begin{array}{l}-0.409 \\
(0.052)\end{array}$ & $\begin{array}{l}-0.297 \\
(0.056)\end{array}$ & $\begin{array}{l}-0.285 \\
(0.050)\end{array}$ \\
\hline Other & $\begin{array}{l}-0.435 \\
(0.052)\end{array}$ & $\begin{array}{l}-0.414 \\
(0.060)\end{array}$ & $\begin{array}{l}-0.364 \\
(0.057)\end{array}$ & $\begin{array}{l}-0.187 \\
(0.059)\end{array}$ & $\begin{array}{l}-0.094 \\
(0.065)\end{array}$ & $\begin{array}{c}-0.071 \\
(0.057)\end{array}$ \\
\hline $\begin{array}{l}\text { Male - Female } \\
\text { (Standard Error) }\end{array}$ & $\begin{array}{l}-0.028 \\
(0.033)\end{array}$ & $\begin{array}{l}-0.060 \\
(0.039)\end{array}$ & $\begin{array}{c}0.014 \\
(0.044)\end{array}$ & $\begin{array}{l}-0.010 \\
(0.049)\end{array}$ & $\begin{array}{l}-0.080 \\
(0.050)\end{array}$ & $\begin{array}{l}-0.047 \\
(0.049)\end{array}$ \\
\hline Observations & 6,699 & 6,786 & 6,726 & 6,699 & 6,786 & 6,726 \\
\hline R-squared & 0.152 & 0.155 & 0.133 & 0.202 & 0.117 & 0.178 \\
\hline Individuals & 3,283 & 3,308 & 3,287 & 3,283 & 3,308 & 3,287 \\
\hline
\end{tabular}

*Notes: This table displays estimates from fixed effects regressions of a dummy variable for having a positive time investment on child gender interacted with a dummy for being in a single-mother household. The omitted category is a household with both biological parents present. The fourth row displays the difference in the male and female interaction coefficients. Each regression controls for the number of biological siblings in the household, CDS wave, a marriage indicator for parents in the same household, dummy variables for having stepparents in/out of the household, and gender interactions with age and age-squared. Standard errors are in parentheses and clustered by individual. 
Table 6: Gender Gaps in Probability of PTI $>0$ by Initial HH Structure

Panel A: Both Parents in HH in Wave 1

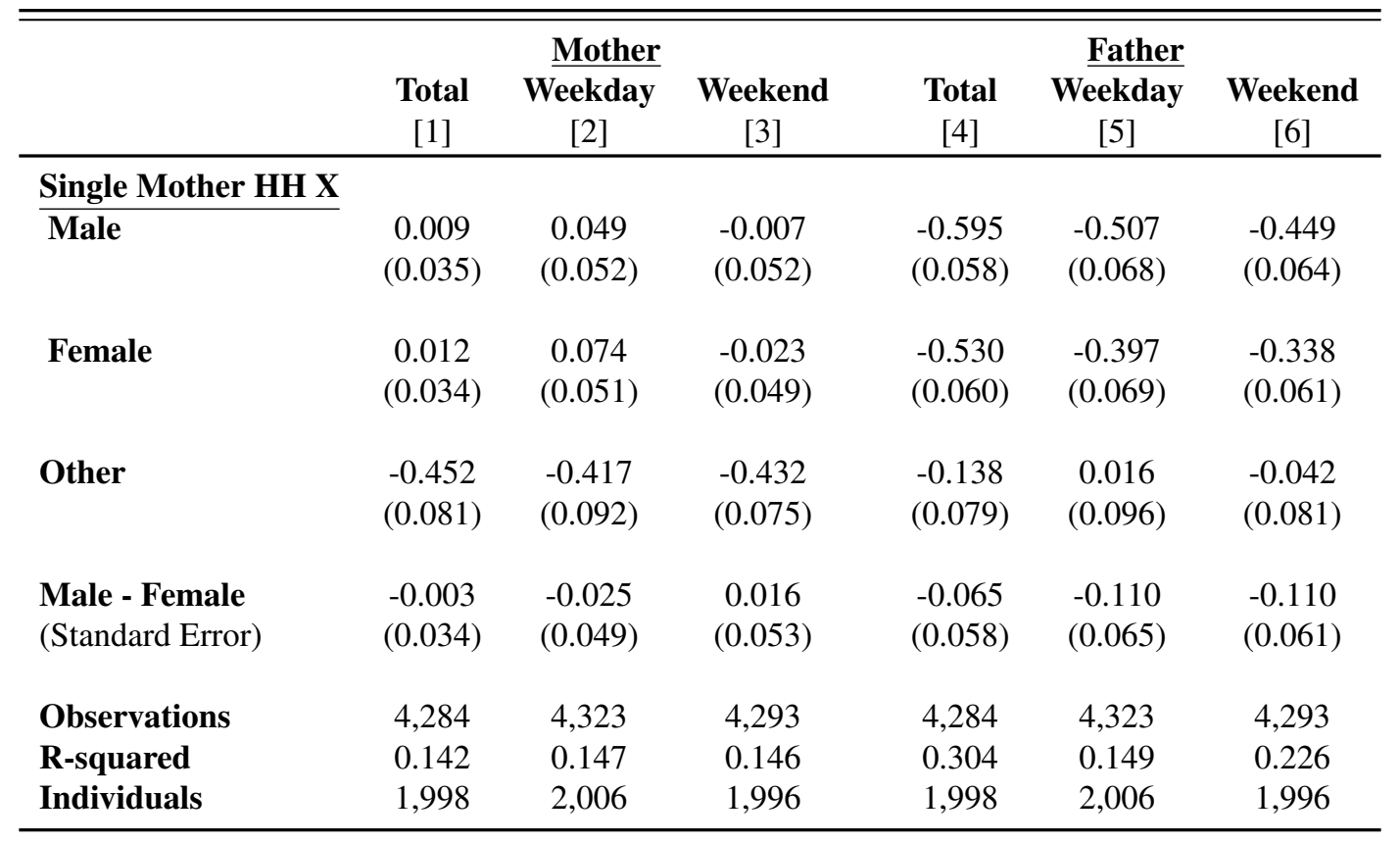

Panel B: Less Than Two Parents in HH in Wave 1

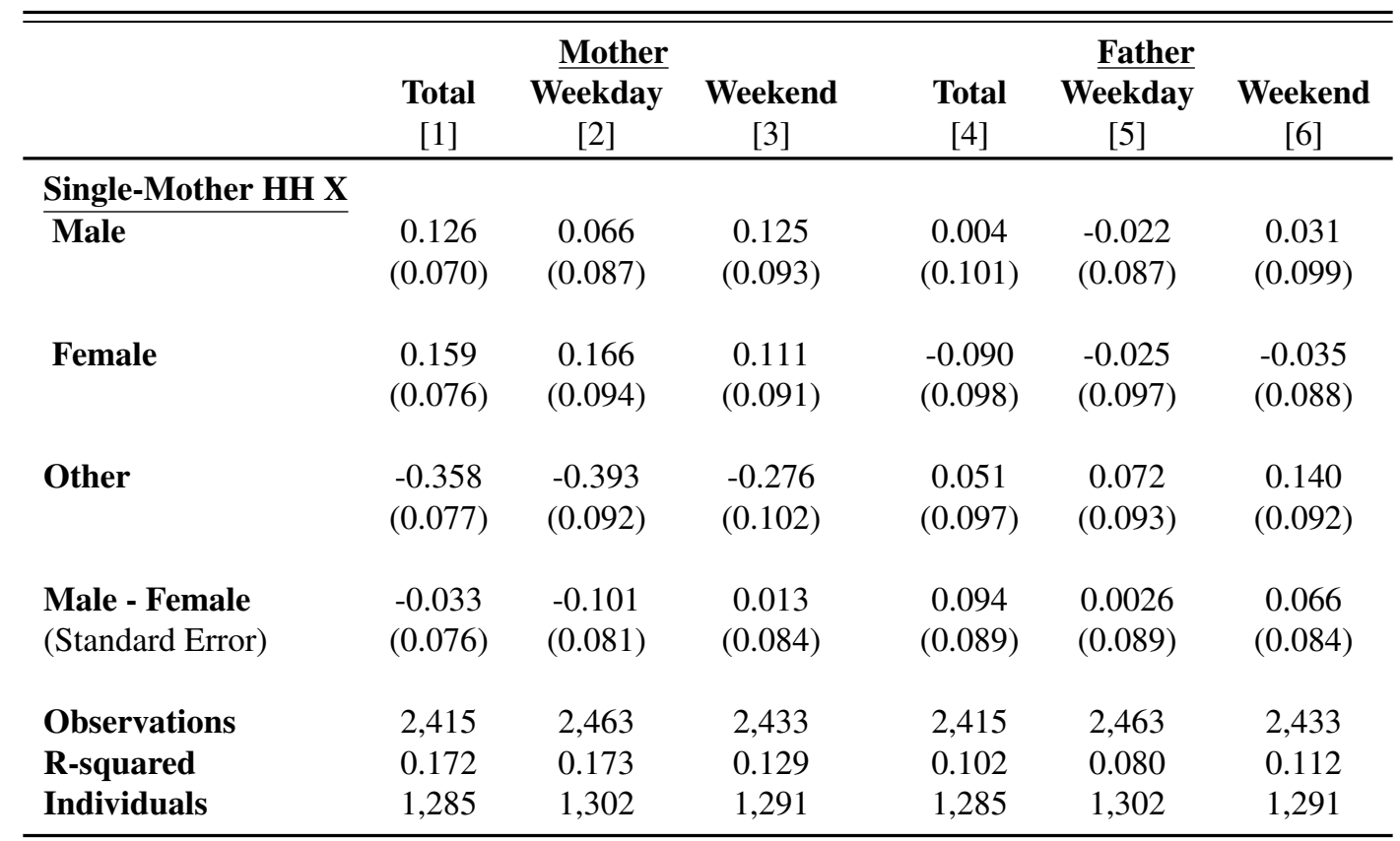

*Notes: This table displays estimates from fixed effects regressions of a dummy variable for having a positive time investment on child gender interacted with a dummy for being in a singlemother household. The omitted category is a household with both biological parents present. Panel A restricts to the sample of children who were in a two-parent household in the first wave, and Panel B restricts to those who were not living with both parents in the first wave. The fourth row of each panel displays the difference in the male and female interaction coefficients. Each regression controls for the number of biological siblings in the household, CDS wave, a marriage indicator for parents in the same household, dummy variables for having stepparents in/out of the household, and gender interactions with age and age-squared. Standard errors are in parentheses and clustered by individual. 
Table 7: Gender Gaps By Age

Panel A: Mothers

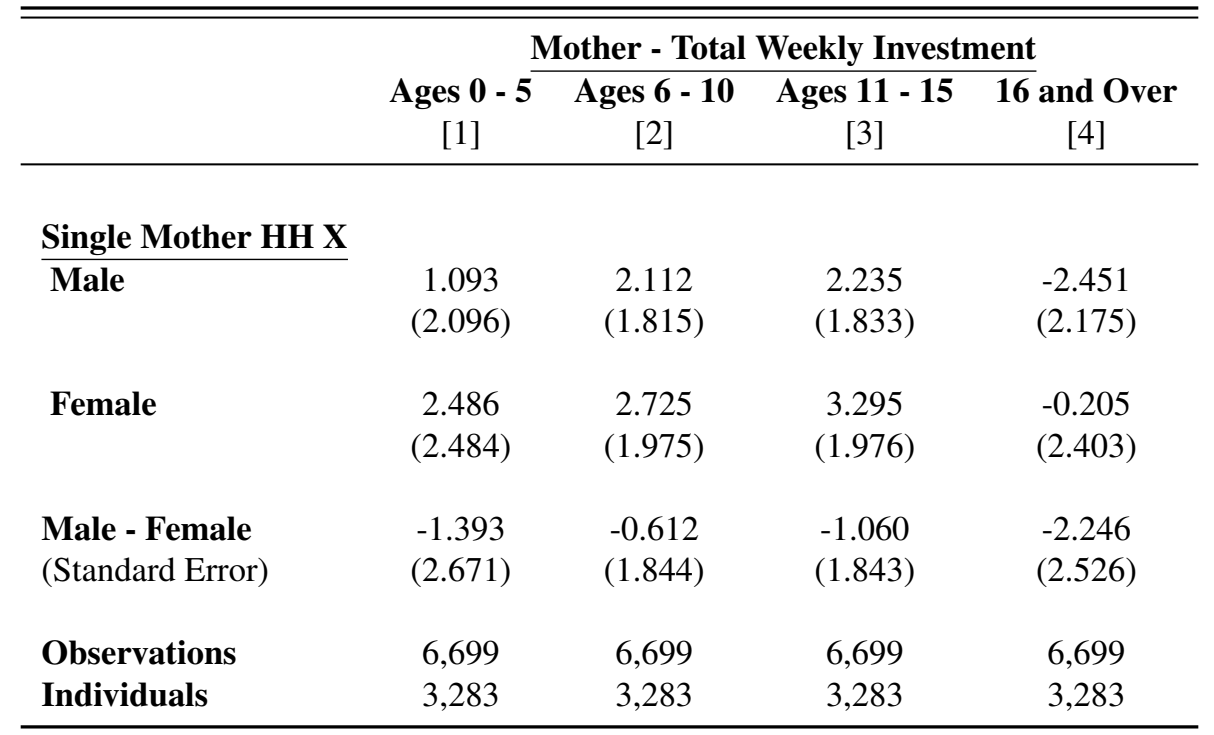

Panel B: Fathers

\begin{tabular}{|c|c|c|c|c|}
\hline & \multicolumn{4}{|c|}{ Father - Total Weekly Investment } \\
\hline & $\begin{array}{c}\text { Ages } 0 \text { - } 5 \\
{[1]}\end{array}$ & $\begin{array}{c}\text { Ages 6 - 10 } \\
{[2]}\end{array}$ & $\begin{array}{c}\text { Ages } 11 \text { - } 15 \\
\text { [3] }\end{array}$ & $\begin{array}{c}\mathbf{1 6} \text { and Over } \\
{[4]}\end{array}$ \\
\hline \multicolumn{5}{|c|}{ Single Mother HH X } \\
\hline Male & $\begin{array}{l}-9.701 \\
(1.428)\end{array}$ & $\begin{array}{l}-7.477 \\
(1.274)\end{array}$ & $\begin{array}{l}-5.321 \\
(1.311)\end{array}$ & $\begin{array}{l}-4.231 \\
(1.577)\end{array}$ \\
\hline Female & $\begin{array}{l}-9.290 \\
(1.251)\end{array}$ & $\begin{array}{l}-5.610 \\
(1.209)\end{array}$ & $\begin{array}{l}-1.991 \\
(1.177)\end{array}$ & $\begin{array}{l}-0.633 \\
(1.325)\end{array}$ \\
\hline $\begin{array}{l}\text { Male - Female } \\
\text { (Standard Error) }\end{array}$ & $\begin{array}{l}-0.411 \\
(1.399)\end{array}$ & $\begin{array}{l}-1.867 \\
(1.211)\end{array}$ & $\begin{array}{l}-3.331 \\
(1.203)\end{array}$ & $\begin{array}{l}-3.598 \\
(1.590)\end{array}$ \\
\hline Observations & 6,699 & 6,699 & 6,699 & 6,699 \\
\hline Individuals & 3,283 & 3,283 & 3,283 & 3,283 \\
\hline
\end{tabular}

*Notes: Each panel displays estimates from a fixed effects regression of total weekly time investments on child gender interacted with a dummy for being in a single-mother household for four different age groups. The omitted category is a household with both biological parents present. The third row of each panel displays the difference in the male and female interaction coefficients. Each regression controls for the number of biological siblings in the household, CDS wave, a marriage indicator for parents in the same household, dummy variables for having stepparents in/out of the household, and gender interactions with age and age-squared. Standard errors are in parentheses and clustered by individual. 
Table 8: Gender Gaps by Race

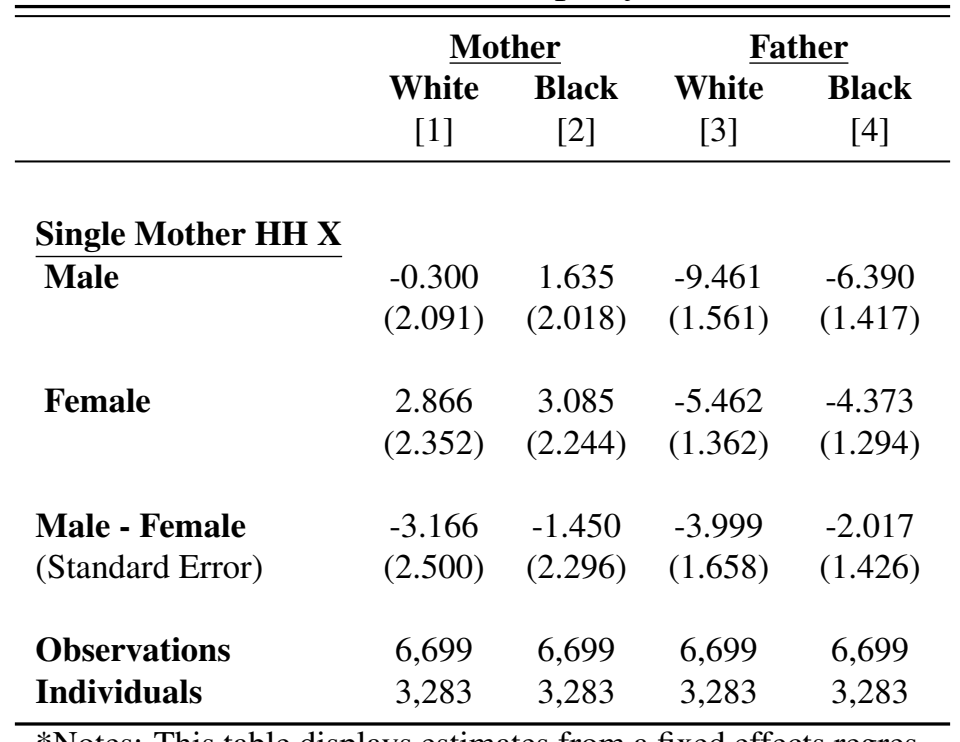

*Notes: This table displays estimates from a fixed effects regression of total weekly time investments on child gender interacted with a dummy for being in a single-mother household by race. The omitted category is a household with both biological parents present. The third row displays the difference in the male and female interaction coefficients. Each regression controls for the number of biological siblings in the household, CDS wave, a marriage indicator for parents in the same household, dummy variables for having stepparents in/out of the household, and gender interactions with age and age-squared.Standard errors are in parentheses and clustered by individual. 
Table 9: Gender Gaps by Activity Type

\begin{tabular}{|c|c|c|}
\hline & $\begin{array}{l}\text { Mother } \\
{[1]}\end{array}$ & $\begin{array}{c}\text { Father } \\
{[2]}\end{array}$ \\
\hline Passive Leisure & $\begin{array}{c}0.222 \\
(0.749)\end{array}$ & $\begin{array}{l}-0.723 \\
(0.461)\end{array}$ \\
\hline Active Leisure & $\begin{array}{l}-0.858 \\
(0.565)\end{array}$ & $\begin{array}{l}-0.753 \\
(0.426)\end{array}$ \\
\hline Entertainment & $\begin{array}{l}-0.060 \\
(0.369)\end{array}$ & $\begin{array}{l}-0.212 \\
(0.330)\end{array}$ \\
\hline Tending to Needs & $\begin{array}{c}0.100 \\
(0.567)\end{array}$ & $\begin{array}{l}-0.483 \\
(0.365)\end{array}$ \\
\hline Obtaining Goods and Services & $\begin{array}{l}-0.182 \\
(0.445)\end{array}$ & $\begin{array}{l}-0.195 \\
(0.265)\end{array}$ \\
\hline Household Activity & $\begin{array}{l}-0.175 \\
(0.222)\end{array}$ & $\begin{array}{l}-0.121 \\
(0.097)\end{array}$ \\
\hline Childcare & $\begin{array}{c}0.183 \\
(0.171)\end{array}$ & $\begin{array}{l}-0.005 \\
(0.015)\end{array}$ \\
\hline $\begin{array}{l}\text { Observations } \\
\text { Individuals }\end{array}$ & $\begin{array}{l}6,699 \\
3,283\end{array}$ & $\begin{array}{l}6,699 \\
3,283\end{array}$ \\
\hline \multicolumn{3}{|c|}{$\begin{array}{l}\text { *Notes: Each estimate is from a fixed effects regression of } \\
\text { weekly time investments for a specific activity category on child } \\
\text { gender interacted with a dummy for being in a single-mother } \\
\text { household. The omitted category is a household with both bi- } \\
\text { ological parents present. Each estimate is from the difference } \\
\text { in the male and female interaction coefficients. Each regression } \\
\text { controls for the number of biological siblings in the household, } \\
\text { CDS wave, a marriage indicator for parents in the same house- } \\
\text { hold, dummy variables for having stepparents in/out of the house- } \\
\text { hold, and gender interactions with age and age-squared. Standard } \\
\text { errors are in parentheses and clustered by individual. }\end{array}$} \\
\hline
\end{tabular}


Table 10: Child Behavior and HH Structure

\begin{tabular}{|c|c|c|c|}
\hline & $\begin{array}{c}\text { Externalizing } \\
\text { Behavior } \\
{[1]}\end{array}$ & $\begin{array}{c}\text { Internalizing } \\
\text { Behavior } \\
{[2]}\end{array}$ & $\begin{array}{c}\text { Positive } \\
\text { Behavior } \\
{[3]}\end{array}$ \\
\hline \multicolumn{4}{|l|}{ Single Mother HH X } \\
\hline$\overline{\text { Male }}$ & $\begin{array}{l}-0.113 \\
(0.134)\end{array}$ & $\begin{array}{c}0.009 \\
(0.136)\end{array}$ & $\begin{array}{l}-0.008 \\
(0.129)\end{array}$ \\
\hline Female & $\begin{array}{c}0.160 \\
(0.136)\end{array}$ & $\begin{array}{c}0.016 \\
(0.145)\end{array}$ & $\begin{array}{l}-0.117 \\
(0.137)\end{array}$ \\
\hline Other & $\begin{array}{l}-0.163 \\
(0.143)\end{array}$ & $\begin{array}{l}-0.092 \\
(0.157)\end{array}$ & $\begin{array}{c}0.146 \\
(0.148)\end{array}$ \\
\hline $\begin{array}{l}\text { Male - Female } \\
\text { (Standard Error) }\end{array}$ & $\begin{array}{l}-0.273 \\
(0.117)\end{array}$ & $\begin{array}{l}-0.007 \\
(0.123)\end{array}$ & $\begin{array}{c}0.110 \\
(0.132)\end{array}$ \\
\hline Observations & 6,060 & 6,058 & 6,078 \\
\hline R-squared & 0.026 & 0.027 & 0.010 \\
\hline Number of Individuals & 3,200 & 3,193 & 3,197 \\
\hline \multicolumn{4}{|c|}{$\begin{array}{l}\text { *Notes: This table displays estimates from fixed effects regressions of } \\
\text { parent rated child behaviors on child gender interacted with a dummy for } \\
\text { being in a single-mother household. The omitted category is a house- } \\
\text { hold with both biological parents present. The fourth row displays the } \\
\text { difference in the male and female interaction coefficients. Each regres- } \\
\text { sion includes controls for the number of biological siblings in the house- } \\
\text { hold, CDS wave, a marriage indicator for parents in the same household, } \\
\text { dummy variables for having stepparents in/out of the household, and gen- } \\
\text { der interactions with age and age-squared. Standard errors are in paren- } \\
\text { theses and clustered by individual. }\end{array}$} \\
\hline
\end{tabular}




\section{Appendix}

(not intended for publication) 


\section{A Supplemental Results}

Table A1: FE Estimates of Gender Gaps with Day of Week FEs

\begin{tabular}{lcccccc}
\hline \hline & $\begin{array}{c}\text { Total } \\
{[1]}\end{array}$ & $\begin{array}{c}\text { Mother } \\
\text { Weekday } \\
{[2]}\end{array}$ & $\begin{array}{c}\text { Weekend } \\
{[3]}\end{array}$ & $\begin{array}{c}\text { Total } \\
{[4]}\end{array}$ & $\begin{array}{c}\text { Father } \\
\text { Weekday } \\
{[5]}\end{array}$ & $\begin{array}{c}\text { Weekend } \\
{[6]}\end{array}$ \\
\hline Single-Mother HH X & & & & & & \\
\hline Male & 1.250 & 0.010 & 0.539 & -7.339 & -0.901 & -1.357 \\
& $(1.711)$ & $(0.273)$ & $(0.359)$ & $(1.245)$ & $(0.175)$ & $(0.317)$ \\
Female & & & & & & \\
& 2.370 & 0.211 & 0.535 & -5.131 & -0.509 & -1.139 \\
Other & $(1.865)$ & $(0.279)$ & $(0.396)$ & $(1.142)$ & $(0.160)$ & $(0.310)$ \\
& & & & & & \\
Male - Female & -7.493 & -1.044 & -1.144 & -2.311 & -0.345 & -0.358 \\
(Standard Error) & $(1.941)$ & $(0.293)$ & $(0.408)$ & $(1.381)$ & $(0.193)$ & $(0.353)$ \\
& -1.120 & -0.200 & 0.004 & -2.207 & -0.392 & -0.218 \\
$\begin{array}{l}\text { Observations } \\
\text { R-squared }\end{array}$ & $(1.617)$ & $(0.244)$ & $(0.372)$ & $(1.084)$ & $(0.159)$ & $(0.288)$ \\
Number of Individuals & & & & & & \\
\hline
\end{tabular}

*Notes: This is a replication of the main fixed effects estimates from Table 3, Panel B, but includes indicators for day of the week. For the total weekly time regression, there is a dummy included for each weekday-weekend day combination, with one combination excluded. Standard errors are in parentheses and clustered by individual. 
Table A2: Gender Gaps in Investments by Initial HH Structure (Day of Week FE)

\begin{tabular}{lcccc}
\hline \hline & \multicolumn{2}{c}{ Both in Wave 1 } & \multicolumn{2}{c}{$\leq \mathbf{2}$ in Wave 1 } \\
& $\begin{array}{l}\text { Mother } \\
{[1]}\end{array}$ & $\begin{array}{c}\text { Father } \\
{[2]}\end{array}$ & {$[3]$} & {$[4]$} \\
\hline Single-Mother HH X & & & & \\
\hline Male & 1.849 & -9.417 & 3.246 & 0.329 \\
& $(2.145)$ & $(1.642)$ & $(3.252)$ & $(1.725)$ \\
& & & & \\
Female & 1.192 & -5.289 & 6.861 & 0.483 \\
& $(2.162)$ & $(1.549)$ & $(3.743)$ & $(1.465)$ \\
Other & & & & \\
& -9.097 & -3.034 & -4.231 & 3.302 \\
Male - Female & $(2.700)$ & $(2.161)$ & $(3.349)$ & $(1.724)$ \\
(Standard Error) & & & & \\
& 0.657 & -4.128 & -3.615 & -0.154 \\
Observations & $(2.037)$ & $(1.534)$ & $(2.896)$ & $(1.642)$ \\
R-squared & & & & \\
Number of Individuals & 4,284 & 4,284 & 2,415 & 2,415 \\
\hline & 0.292 & 0.160 & 0.224 & 0.080 \\
& 1,998 & 1,998 & 1,285 & 1,285 \\
\hline
\end{tabular}

*Notes: This is a replication of the main fixed effects estimates by initial household structure from Table 4, but includes indicators for day of the week. For the total weekly time regression, there is a dummy included for each weekday-weekend day combination, with one combination excluded. Standard errors are in parentheses and clustered by individual. 